Universidad de Lima

Facultad de Ciencias Empresariales y Económicas

Carrera de Contabilidad

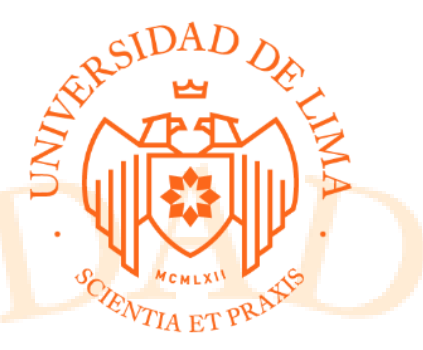

\title{
ANÁLISIS E INTERPRETACIÓN DE LOS ESTADOS FINANCIEROS EN LA TOMA DE DECISIONES. CASO EXSA S.A. PERIODO 2015 - 2017
}

Trabajo de suficiencia profesional para optar el Título Profesional de Contador

Público

Julie Elizabeth Cuya Pando

Código 19970478

Asesor

Carlos Paredes Reátegui

Lima - Perú

Noviembre de 2018 


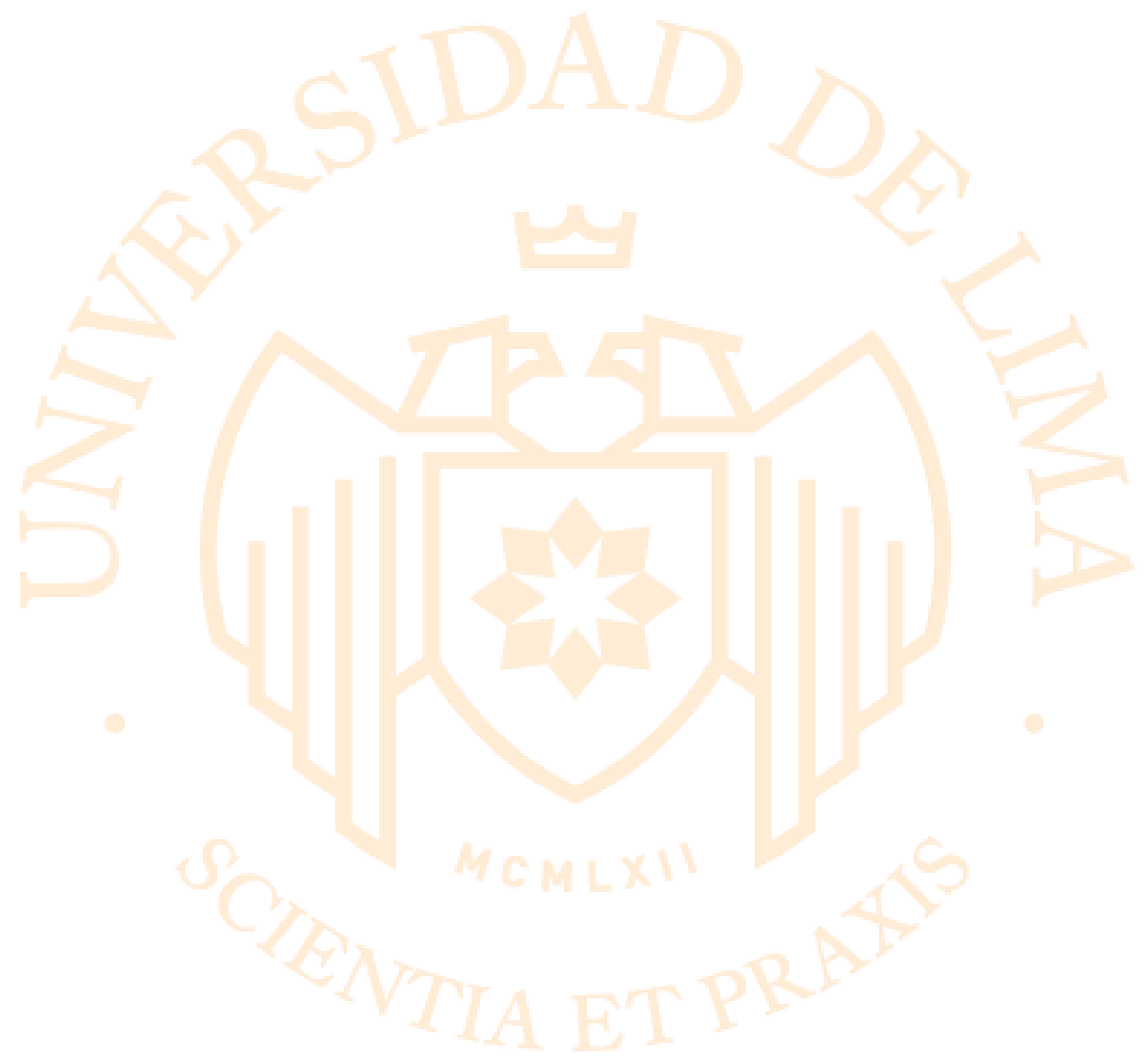




\section{ANÁLISIS E INTERPRETACIÓN DE LOS ESTADOS FINANCIEROS EN LA TOMA DE DECISIONES. CASO EXSA S.A. PERIODO 2015 - 2017}




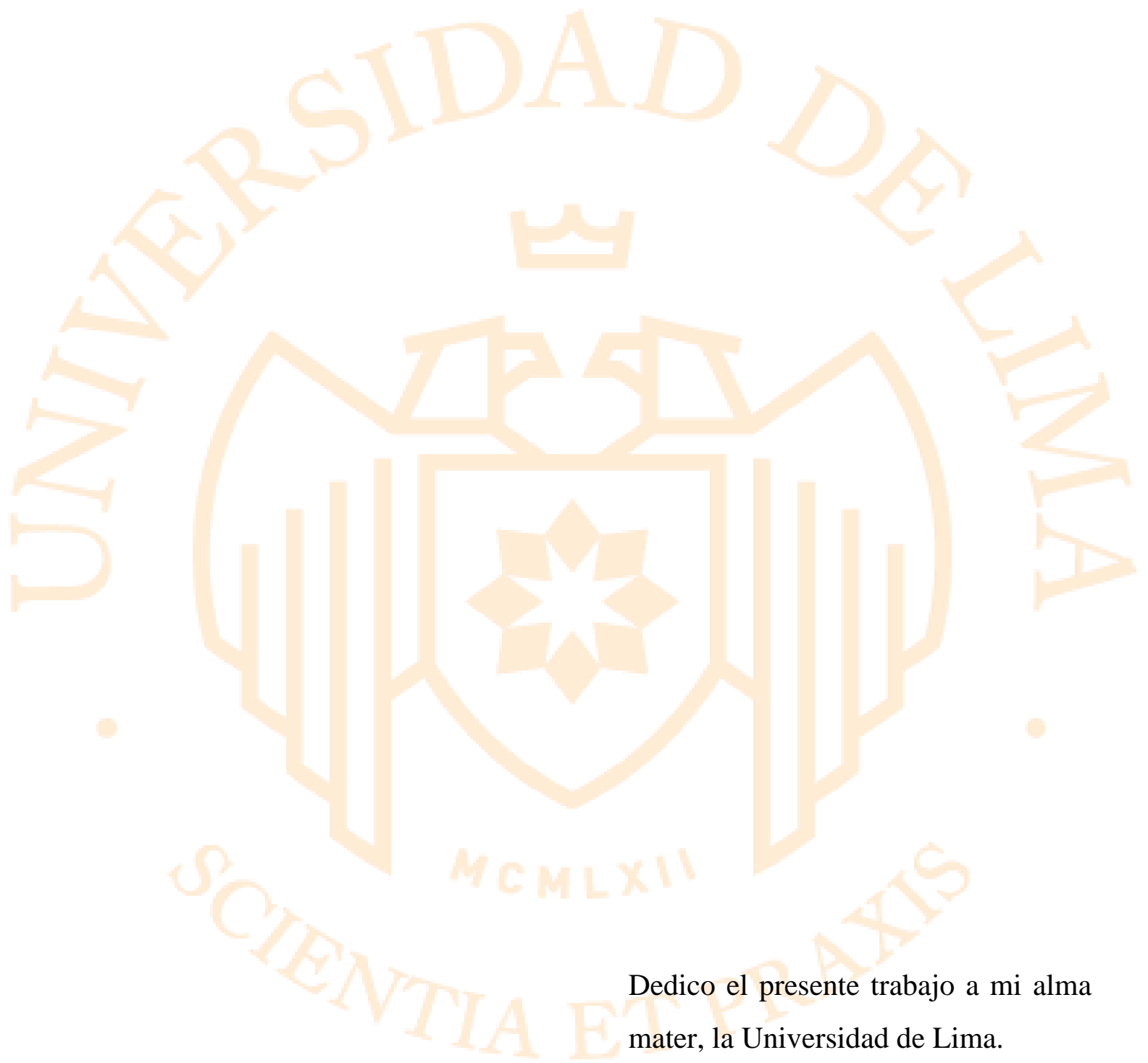




\section{TABLA DE CONTENIDO}

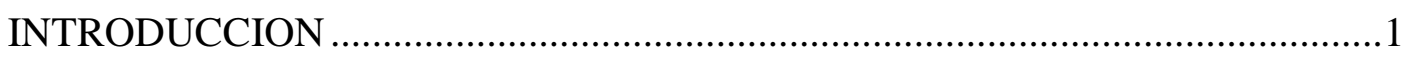

CAPITULO I: ANTECEDENTES DE LA ENTIDAD ........................................3

Identificación y actividad económica de la entidad...............................................4

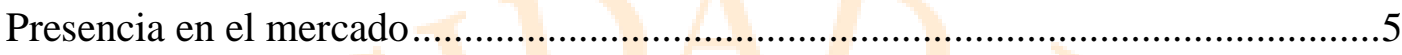

CAPITULO II DESCRIPCION Y OBJETIVOS DEL TRABAJO DE SUFICIENCIA PROFESIONAL .................................................................................99

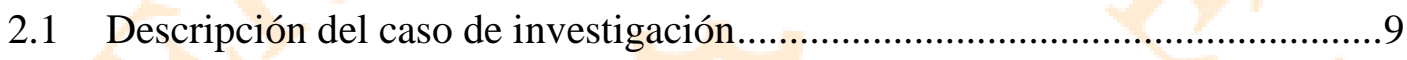

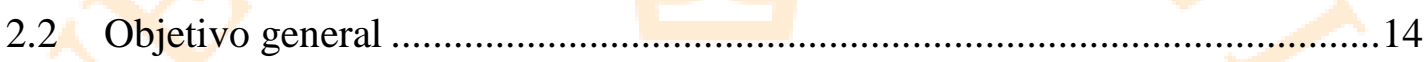

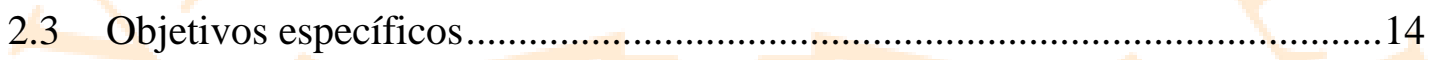

CAPITULO III MARCO METODOLOGICO .....................................................15

3.1 Metodología de recolección de la información..............................................15

3.2 Metodología de análisis de la información ....................................................16

CAPITULO IV ANALISIS Y PRESENTACION Y DISCUSION DE

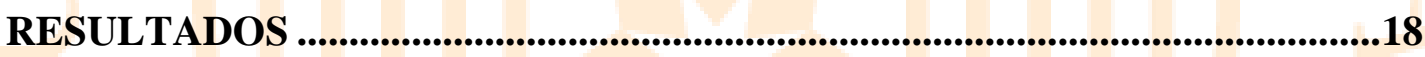

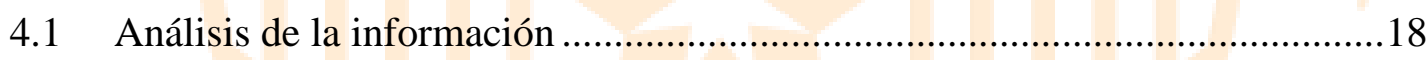

4.2 Presentación y discusión de resultados ...........................................................35

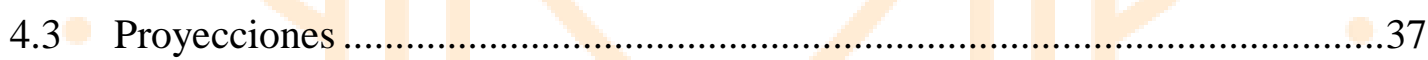

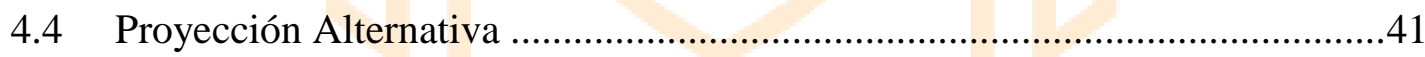

4.5 Impacto de las NIIF 9, 15 y 16 en los Estados Financieros Proyectados42

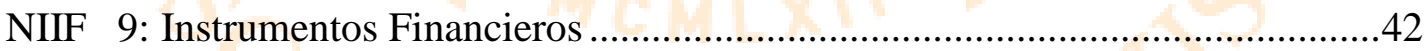

NIIF 15: Ingresos procedentes de contratos con clientes .....................................43

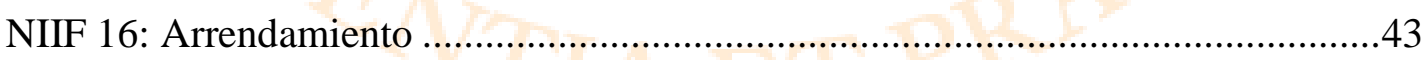

CAPITULO V: CONCLUSIONES Y RECOMENDACIONES .......................45

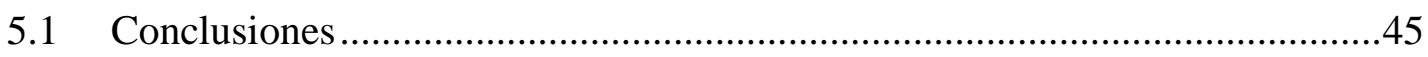

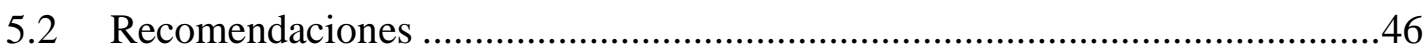

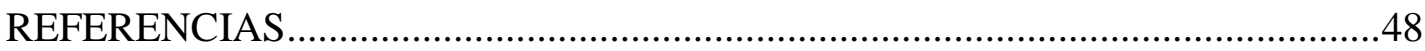

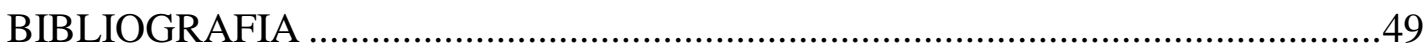

ANEXOS 50 


\section{ÍNDICE DE FIGURAS}

Figura 2.1 Principales Empresas Exportadoras del Perú ...........................................12

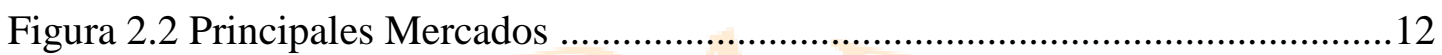

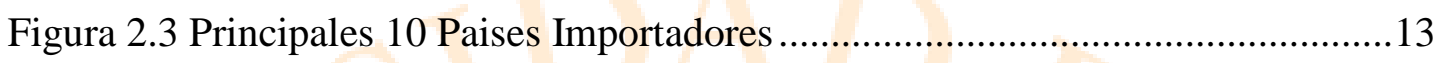

Figura 2.4 Principales 10 Países Exportadores ....................................................... 13

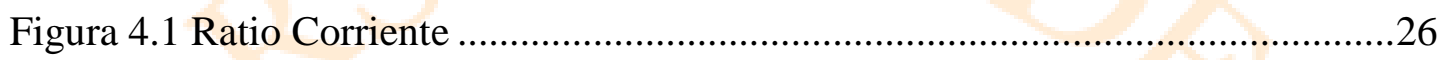

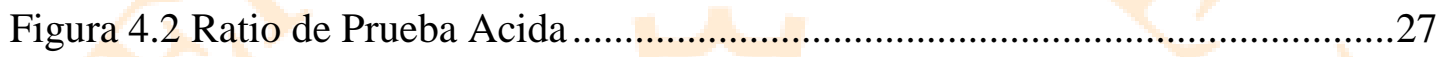

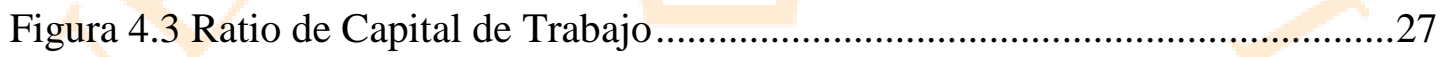

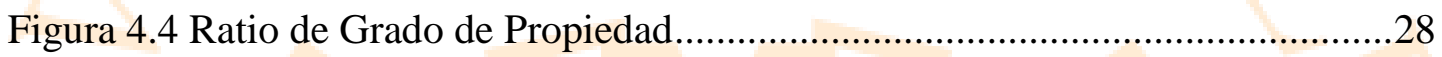

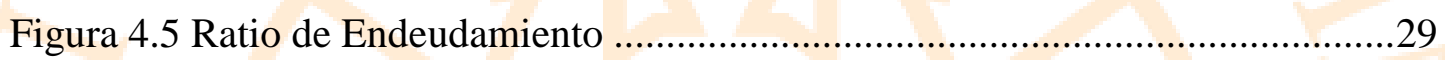

Figura 4.6 Periodo Promedio de Cobro ................................................................29

Figura 4.7 Periodo Promedio de Inventarios …...................................................... 30

Figura 4.8 Periodo Promedio de Cuentas por Pagar .................................................30

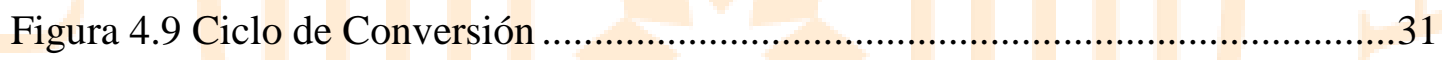

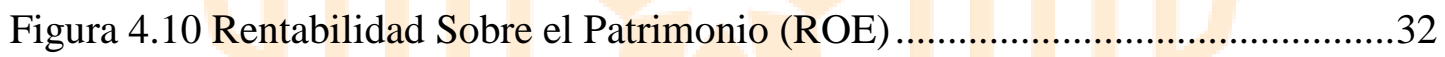

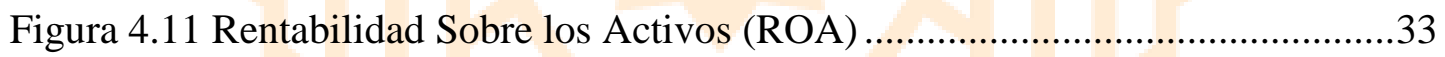

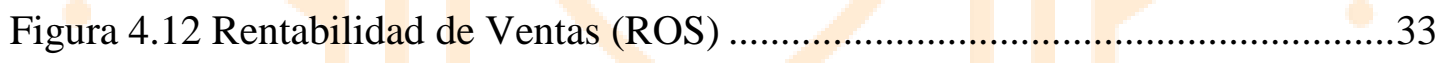

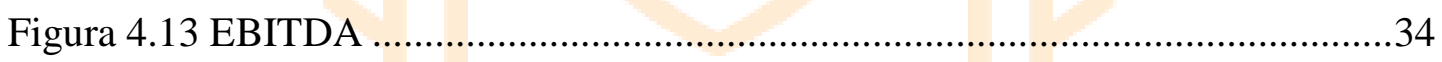




\section{ÍNDICE DE ANEXOS}

Anexo 2. Estado de Situación Financiera ..............................................................51

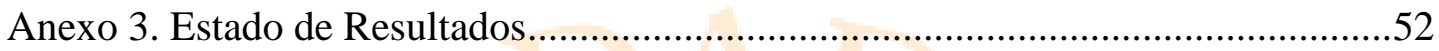

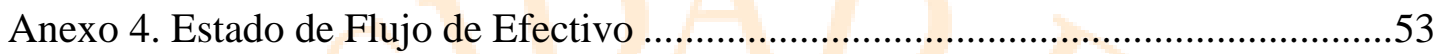

Anexo 5. Estado de Cambios en el Patrimonio ............................................................54 


\section{INTRODUCCION}

El presente trabajo se enfoca en el análisis e interpretación de los estados financieros, los cuales proporcionan información relevante para determinar la salud financiera, el estado actual de una empresa y aporta una valoración para facilitar la toma de decisiones, con relación a los objetivos de la empresa.

Para poder efectuar una evaluación financiera se iniciará haciendo uso de información tanto cualitativa como cuantitativa, con los cuales se elaborarán los diversos indicadores financieros de rentabilidad, liquidez y endeudamiento, con el fin de determinar cuál ha sido el desempeño financiero de la compañía, así como poder comparar razones pasadas y futuras esperadas para la misma.

Las empresas pueden detectar sus puntos débiles y fortalecerlos a través del uso del análisis financiero, el cual es una herramienta gerencial y analítica necesaria para toda actividad empresarial, determina las condiciones financieras en el presente, la gestión de los recursos financieros disponibles, maximizar sus oportunidades a través de decisiones efectivas y eficientes, por ello garantizar el logro del cumplimiento de sus objetivos y asegurar su permanencia en un mundo empresarial tan competitivo como el hoy en día.

En adelante efectuaremos el análisis financiero haciendo uso de los estados financieros individuales auditados de a la empresa EXSA S.A.

En el primer capítulo se refiere a los antecedentes de la entidad, donde se presenta la información de la compañía y de la industria.

En el segundo capítulo se desarrolla el tema a abordar, objetivo general, especifico.

En el tercer capítulo, se expone la metodología del trabajo, abarcando el tipo, diseño, la metodología y la forma como se ha recolectado la información seguida en el análisis de la información.

En el cuarto capítulo se ordena y clasifica y presenta los resultados del análisis de la información como también la discusión de resultados. 
Finalmente, en el quinto capítulo se propone conclusiones y recomendaciones, que se obtiene luego de haber hecho un análisis exhaustivo del funcionamiento de la empresa. 


\section{CAPITULO I: ANTECEDENTES DE LA ENTIDAD}

La empresa EXSA S.A. fue constituida en 1954 e inicio sus operaciones en Lurín, con la razón social de Explosivos S.A., sirviendo al Perú desde esa fecha por más de 40 años, haciendo uso de los más exigentes niveles de seguridad y tecnología, tanto en la producción, como en la asistencia técnica.

En pocos años diversificaron y ampliaron sus líneas de producción, lo que hace posible que hoy en día ofrezcan una gama completa de explosivos para todo tipo de voladura. Como parte de su desarrollo y crecimiento empresarial implementaron dos unidades productivas en las ciudades de Tacna y Trujillo, dedicadas satisfacer oportunamente los requerimientos de sus clientes en dichas zonas.

La compañía con la finalidad de satisfacer la demanda de los clientes a través de mayor modernización y especialización incorporó líneas de productos de Accesorios de Voladura y el Servicio de Voladura.

En 1960 funda la Compañía Peruana de Electrodos Oerlikon S.A. para la producción de electrodos y otros consumibles para soldadura en general, luego fue absorbida por EXSA S.A. en 1971. Convirtiéndose así en su División de Soldadura, el cual en la actualidad es el mayor proveedor de soldaduras de calidad de la industria nacional, y ofrece a sus clientes una amplia gama de productos, que se aplican en todo tipo de metales ferrosos y no ferrosos, así como una completa línea de Máquinas y Accesorios para Soldadura.

En 2004 EXSA obtiene el certificado ISO 14001 para su Sistema de Gestión Ambiental, siendo fiel a su compromiso tanto con el cuidado del medio ambiente como por las comunidades que nos rodean.

Para 2007, a raíz de la fusión de la División de Soldaduras y su subsidiaria Valores Lurín S.A.C, se crea SOLDEXA, la cual se incorpora al grupo de empresas fundadoras de la Asociación de Buenos Empleadores (ABE) y obtiene la certificación OHSAS 18001 para su Sistema de Seguridad y Salud Ocupacional.

EXSA inicia su plan de expansión internacional, es por ello que a partir del 2010 inicia sus operaciones en países como Panamá, Colombia, etc. 
En la actualidad, EXSA cuentan con almacenes regionales ubicados en las ciudades de Lima, Arequipa, Ilo, Trujillo y Tacna dedicados a comercializar soldaduras, electrodos y máquinas de soldar, satisfaciendo las necesidades de sus clientes a nivel nacional (EXSA,2017).

\section{Identificación y actividad económica de la entidad}

A continuación, se detallará todo lo relacionado con la identificación de la empresa EXSA.

\begin{tabular}{|l|l|}
\hline DETALLE & DESCRIPCION \\
\hline Razón Social & EXSA S.A. \\
\hline RUC & 20100094135 \\
\hline Página WEB & https://exsa.net \\
\hline Giro del negocio & $\begin{array}{l}\text { fabricación, venta local y exportación de } \\
\text { explosivos, productos químicos, metalúrgicos } \\
\text { y materias plásticas; prestación de servicios de } \\
\text { voladura, todo tipo de servicios a empresas } \\
\text { mineras. }\end{array}$ \\
\hline Fecha de Constitución & 25 de febrero de 1954 \\
\hline Dirección Fiscal & Calle las Begonias 415, San Isidro (Lima, Perú) \\
\hline Accionistas y participación & 114,429 Acciones comunes (Al 31.12.2017) \\
\hline
\end{tabular}

Fuente: EXSA S.A; https://exsa.net

Elaboración propia.

Esquema de accionistas con participación porcentual mayor a 5\%

\begin{tabular}{|c|c|c|}
\hline Accionistas & $\begin{array}{c}\text { Participacipon } \\
\text { Porcentual }\end{array}$ & Nacionalidad \\
\hline Inversiones BRECA & $81 \%$ & Peruana \\
\hline MINSUR & $10.90 \%$ & Peruana \\
\hline $\begin{array}{c}\text { Futura Consorcio } \\
\text { Inmobiliario }\end{array}$ & $6 \%$ & Peruana \\
\hline
\end{tabular}

Fuente y elaboración: Memoria EXSA S.A. (2017)

La Compañía ha adquirido acciones de otras empresas peruanas y extranjeras a través de la creación de empresas bajo su control a través de acciones y control conjunto de negocios con terceros, dichas empresas se desempeñan en actividades relacionadas principalmente con la comercialización de dinamita y derivados. 
Al 31 de diciembre 2017 y 2016, las inversiones en subsidiarias que mantiene la Compañía son las siguientes:

\begin{tabular}{|c|c|c|c|}
\hline Subsidiarias & \begin{tabular}{|c|} 
Participación en \\
la Propiedad al \\
31 de Diciembre \\
2017 \\
$\%$ \\
\end{tabular} & Domicilio & Actividad Económica \\
\hline $\begin{array}{c}\text { International Blasting } \\
\text { Services Inc. }\end{array}$ & 100 & Panamá & $\begin{array}{l}\text { Comercialización de los productos que } \\
\text { produce la Compañía. }\end{array}$ \\
\hline EXSA Colombia S.A.S. & 100 & Colombia & $\begin{array}{l}\text { Realiza Actividades comerciales para la } \\
\text { fragmentación de roca y otros relacionados }\end{array}$ \\
\hline $\begin{array}{l}\text { Holding EXSA S.A. y } \\
\text { Subsidiaria }\end{array}$ & 99.90 & Perú & $\begin{array}{l}\text { Vehículo de inversión dedicado a controlar el } \\
100 \% \text { de las actividades de EXSA Chile SPA }\end{array}$ \\
\hline
\end{tabular}

Fuente y elaboración: Estados financieros Separados y Auditados EXSA S.A. 2017

\section{Presencia en el mercado}

Las empresas multinacionales juegan un papel importante en el proceso de globalización, considerando que a través de ellas se canalizan los mayores flujos inversión, capitales y comercio, lo cual ha traspasado fronteras y afectado la situación de todos los actores nacionales.

La economía peruana ha presentado dos fases diferenciadas de crecimiento en lo que va del siglo XXI. Entre 2002 y 2013, el Perú fue uno de los países con mayor dinamismo en Latinoamérica, con una tasa de crecimiento promedio del PBI de $6.1 \%$ anual, se tuvo un escenario de alto crecimiento y baja inflación, sin embargo, entre 2016 y 2017 la economía se desaceleró en un promedio de 3.1\% anual, básicamente por consecuencia de la caída del precio internacional de las materias primas, entre ella el cobre, principal producto de exportación peruano (Perú Panorama General,2017, Parr 1). Durante el primer semestre del 2018 el crecimiento alcanzado por la economía nacional fue de $4.29 \%$, con respecto al periodo similar del 2017, a pesar de la disminución en el sector de Minera e hidrocarburos en $4.57 \%$, el cual fue originado por la menor actividad minera metálica, según el Instituto Nacional de Estadística e Informática (INEI) para Julio del presente año la economía creció $2.3 \%$ respecto al mismo mes del año anterior, con dicha expansión la economía peruana acumulo un 
crecimiento de $4 \%$ entre enero y julio 2018, cuyo resultado fue impulsado básicamente por los sectores no primarios (Construcción 5\% y manufactura no primaria 3.4\%) con un crecimiento de $3.9 \%$, asociados a la demanda interna, indicado por el Ministerio de Economía y Finanzas (MEF).

Debemos de tener en cuenta que el Perú es uno de los destinos más atractivos para la inversión minera en el mundo, según el ranking del Fraser Institute 2017, el cual determina cuales son los países que más atraen a los inversionistas de dicha actividad económica, lo cual es amparado por alguna de las minas más grandes e importantes a nivel mundial, como por ejemplo Antamina, Uchucchacua, Volcan, Hochschild, etc.

EXSA S.A.es una empresa peruana líder en la oferta de soluciones exactas en la fragmentación de roca para la industria de la minería e infraestructura, la cual tiene presencia corporativa en Perú, Chile, plantas en Lurín, Trujillo y Tacna, además exporta a varios países de la región. Para el desarrollo de sus operaciones la compañía ha realizado inversiones en acciones en otras empresas peruanas y extranjeras, es decir tiene presencia tanto nacional como internacional (Perú, Colombia, Chile, Panamá).

En cuanto a las líneas de producción que comercializa EXSA en el mercado internacional más del $93 \%$ del total de las exportaciones la compañía, durante los últimos 10 años se concentran en las líneas de dinamita, ANFO y emulsiones encartuchadas, según lo indicado por la Superintendencia Nacional de Aduanas y de Administración Tributaria (SUNAT).

En el año 2017, las exportaciones se redujeron en 3.6\% con respecto al año 2016, sustentado principalmente por la caída en ventas en Bolivia (dinamitas y emulsión encartuchada). Sin embargo, se incrementaron las ventas a Estados Unidos y se generó la apertura de un nuevo canal de distribución en Bolivia, los cuales ayudaron a reducir el déficit.

A continuación, se detalla tipos de productos clasificados por líneas. 


\begin{tabular}{|c|c|c|}
\hline Altos explosivos & Agentes de voladura & Sistemas de iniciación \\
\hline Booster & Anfo & Conector \\
Cordón detonante & Emulsión a granel & Detonador Eléctrico \\
Dinamita & & Detornador ensamblado \\
Emulsión & & Detornador no eléctrico \\
Encartuchada & & Explosivos Sismicos \\
& & Fulminante \\
& & Mecha de seguridad \\
& & Mecha rápida \\
& & Tubo de choque \\
\hline
\end{tabular}

Fuente y elaboración: Memoria EXSA 2017

Se precisa que dependiendo del proyecto se utilizan distintos tipos de productos de la cartera de EXSA, por ejemplo, para operaciones subterráneas se utilizan detonadores eléctricos, tubos de choque y otros productos requeridos para llevar acabo la fase de iniciación de la dinamita o emulsión encartuchada, anfo o emulsión encartuchada, etc.

Según el reporte de sostenibilidad de EXSA 2017, sus Unidades de Negocio son:

- Clientes Adjudicados por licitación: se encuentran en el sector de construcción, Oil \& Gas y minería en Estados Unidos y Canadá. Exaditch proporciona una eficiente fragmentación de roca, lo cual se traduce en un ahorro sustancial de energía y costos para los clientes.

- Clientes SPOT: Con dichos clientes la relación es transaccional, considerando que envían sus solicitudes de cotización.

- Unidad de Negocio Subterráneo: Está constituida por clientes de minería subterránea, de infraestructura y regionales, con quienes no suele trabajar mediante contratos, sino a través de órdenes de compra regulares para el abastecimiento de productos y servicios especializados.

- Unidad de Negocios de Nuevos Servicios: Se encarga de brindar a todos sus clientes, independientemente del segmento al que pertenezcan, soluciones integrales en servicios relacionados a la fragmentación de roca. Entre los nuevos servicios que se ofrecen destacan la construcción de polvorines, construcción de canchas de nitrato, silos, servicios de minado, perforación y voladura, entre otros. 
- Servicio Integral de Voladura (SIVE): este servicio ha sido diseñado para que los clientes de operaciones de tajo abierto le transfieran la responsabilidad de sus procesos de voladura a EXSA. SIVE tiene como enfoque garantizar la continuidad de las operaciones de los clientes de EXSA.

La comunicación con los clientes es multicanal, se utilizan los medios como el internet, correo, teléfono, folletos para los asuntos del día a día y reuniones de mejora continua, de apertura y de expectativas para evaluar la continuidad de las operaciones y satisfacción de los clientes. Mantiene contacto en ferias, congresos, cursos relacionados a temas de minería y para la atención personalizada de clientes en mina se tienen equipos de servicio liderados por un Jefe de Operación o Residente.

Finalmente, EXSA ha logrado exportar sus productos, durante los últimos 10 años, a Argentina, Bolivia, Brasil, Chile, Colombia, Ecuador, Estados Unidos, Haití, Islas Caimán, Panamá y República Dominicana. 


\section{CAPITULO II DESCRIPCION Y OBJETIVOS DEL TRABAJO DE SUFICIENCIA PROFESIONAL}

\subsection{Descripción del caso de Investigación}

La presente evaluación financiera analiza de manera objetiva el estado de salud económica y financiera de la empresa EXSA S.A.

El resultado de este análisis financiero sirve para aplicar medidas correctivas a fin de reconocer y superar las debilidades y aprovechar de la mejor manera las fortalezas que tiene la compañía a fin de llevar cabo un plan de acción.

Partimos de una revisión del mercado al cual está dirigida EXSA, a fin de efectuar el análisis desde el origen para su mejor comprensión.

La industria de los explosivos en el Perú forma parte del sub sector de manufactura no primaria y clasificada dentro del grupo de Productos químicos, caucho y plásticos (Banco Central de Reserva del Perú [BCRP], 2018). Los principales clientes de las empresas dedicadas a la industria de los explosivos son básicamente las constructoras y las empresas pertenecientes al sector minero, cabe resaltar que la mayor parte de las ventas de las empresas dedicadas a la venta de explosivos provienen del sector minero.

Según los señalado por Gustavo Gómez - Sánchez, Gerente General de EXSA Perú (2017) el 95\% de los clientes de EXSA son mineros, es así que en este ciclo de decrecimiento su iniciativa es innovar para adaptarse a las necesidades del mercado nacional y mundial (Diario Gestión, 2015).

Según los reportes de estudios económicos publicados por el banco Scotiabank, en el 2018 el crecimiento sectorial será desigual, pero generalizado, a diferencia de los dos últimos años, el crecimiento del PBI dependerá principal de los sectores no primarios, es decir a sector al cual corresponde la manufactura de explosivos.

Teniendo la base de las cinco fuerzas de Porter, se desarrollan a continuación, con el fin de sintetizar el entorno que determina y caracteriza el mercado de EXSA S.A. 
- Poder de negociación de los compradores o clientes, la crisis en los precios de los minerales, los clientes exigían productos que se ajusten más a sus necesidades, con menor precio y que pudieran generar ahorros en sus operaciones; lo mismo que provocó que las empresas tuvieran que desarrollar nuevas tecnologías y actuar más proactivamente de cara hacia las necesidades de los clientes.

El éxito del desarrollo y la tecnología QUANTEX permitió a EXSA fortalecer su área I+D y su proceso de innovación, es por ello que enfoca la innovación de la organización no en innovar por innovar si no que sea práctico y rentable, como es el caso de la tecnología de productos menos contaminantes y resistentes como EXSADITCH, el cual es un producto $100 \%$ peruano desarrollado por la empresa y tiene una vida útil de 18 meses, el cual fue creado para atender, inicialmente, al sector construcción, Oil \& Gas y minería en Estados Unidos y Canadá. Dicho producto proporciona una eficiente fragmentación de roca, lo cual se traduce en un ahorro sustancial de energía y costos para los clientes (Diario El comercio, 2016).

- La gestión con proveedores y contratistas está enmarcada en la política de compras que establece los lineamientos bajo los cuales se deben ejecutar las adquisiciones, cumpliendo con las mejores prácticas de clase mundial. La compañía logro a gran medida la negociación con sus proveedores, así que logra abastecerse de materia prima al menor costo posible.

Es importante resaltar que el proceso de Evaluación califica al proveedor en distintos aspectos: Comercial, Finanzas, Legal, Capacidad Operativa, Gestión de la Calidad y Sustentabilidad (incluye Seguridad, Salud Ocupacional, Medio Ambiente).

- Amenaza de nuevos entrantes, el mercado mundial de explosivos está dominado por ocho grandes empresas Austin Powder, Maxam, EPC Europe, Orica Mining Services, Incitec Pivot, AECI, Sasol y la chilena Enaex (Fraser Institute, 2016) las cuales poseen operaciones en mercados 
de mayor desarrollo minero en el mundo. El Perú es uno de los países latinoamericanos con mayor atractivo para dichas empresas, básicamente porque nuestro país está posicionado como un actor importante en la minería global, actualmente no son las mundialmente reconocidas, empresas antes indicadas, quienes poseen mayor participación de mercado de la industria de explosivos en el Perú, si no las empresas peruanas EXSA y FAMESA.

Se debe de tener en consideración que el estado peruano intenta reducir la burocracia en el proceso de emitir nuevos permisos que impulsen la actividad minera, lo cual podría ser una amenaza para las dos actuales principales proveedoras del sector de los explosivos en el Perú.

Cabe mencionar que ambas empresas peruanas cuentan con presencia tanto nacional como internacional, considerando que están en un proceso de expansión.

- Amenaza de productos sustitutos, en un contexto de conflictos medioambientales el equipo de EXSA desarrollo productos alternativos, los cuales producen $18 \%$ menos la emisión de gases de efecto invernadero, así como reducción de gases por efecto de voladura y menor efecto de vasodilatación, lo que aliviará los comunes dolores de cabeza en los manipuladores de dinamita. Dicho producto ha tenido una gran aceptación, logrando el $40 \%$ la cuota nacional, sustentado en clientes como Southern Cooper Perú, Yanacocha; Minsur; Hudbay, etc. EXSA apuesta por la innovación, la cual es un pilar de desarrollo.

- Rivalidad competitiva en la industria, en Perú, el competidor directo de EXSA es FAMESA, ambas compiten a la par en la exportación de explosivos. Sin embargo, en el caso del sistema de iniciación, FAMESA ha desarrollado múltiples destinos para los mismos, puesto que son de producción propia, lo que les permitió poder llegar a mercados internacionales de forma más competitiva, lo cual representaba una amenaza para EXSA, considerando que FAMESA ha estado enfocada en 
la producción de sistemas de iniciación que son productos que se pueden exportar forma más fácil, de manera más económica y competitiva en los demás países, en ese sentido a partir del presente año EXSA cuenta con una planta de iniciación, este proyecto inicio hace un par de años y hoy en día es una realidad, posicionándose como un competidor de alto nivel internacional que ofrece soluciones personalizadas.

\section{Comercio Perú}

Figura 2. 1 Principales Empresas Exportadoras del Perú

\begin{tabular}{|c|c|}
\hline EMPRESA & $\% \operatorname{Var} 17-16$ \\
\hline EXSA & $5 \%$ \\
\hline FAMESA & $-31 \%$ \\
\hline
\end{tabular}

Fuente: SUNAT

Figura 2. 2 Principales Mercado

\begin{tabular}{|l|r|r|r|}
\hline Mercado & \% Var 17-16 & $\begin{array}{c}\text { \% } \\
\text { Part.17 }\end{array}$ & $\begin{array}{c}\text { FOB } \\
\text { 17miles }\end{array}$ \\
\hline Ecuador & $-10 \%$ & $37 \%$ & $1,215.57$ \\
\hline Bolivia & $-37 \%$ & $30 \%$ & 988.53 \\
\hline Estados Unidos & - & $9 \%$ & 621.51 \\
\hline Chile & $-12 \%$ & $14 \%$ & 446.75 \\
\hline
\end{tabular}

Fuente: SUNAT 


\section{Comercio Mundial}

Figura 2. 3 Principales 10 Países Importadores

\begin{tabular}{|r|l|r|r|}
\hline$n^{\circ}$ & País & \%Part.15 & $\begin{array}{c}\text { Total } \\
\text { Imp.2015 } \\
\text { (millon } \\
\text { US\$) }\end{array}$ \\
\hline 1 & México & $18 \%$ & 117.15 \\
\hline 2 & Canadá & $13 \%$ & 100.23 \\
\hline 3 & Estados Unidos & $8 \%$ & 56.77 \\
\hline 4 & Australia & $5 \%$ & 29.73 \\
\hline 5 & Noruega & $5 \%$ & 31.71 \\
\hline 6 & Suecia & $4 \%$ & 28.9 \\
\hline 7 & Kazajstán & $4 \%$ & 20.93 \\
\hline 8 & Singapúr & $2 \%$ & 18.86 \\
\hline 9 & Alemania & $2 \%$ & 19.52 \\
\hline 10 & Francia & $2 \%$ & 11.55 \\
\hline 1000 & Otros Paises & $37 \%$ & 346.43 \\
\hline
\end{tabular}

Fuente: COMTRADE

Figura 2. 4 Principales 10 Países Exportadores

\begin{tabular}{|c|c|c|c|c|}
\hline$n^{0}$ & País & $\% \operatorname{Var} 15-14$ & $\%$ Part.15 & $\begin{array}{c}\text { Total } \\
\text { Imp.2015 } \\
\text { (millon } \\
\text { US\$) }\end{array}$ \\
\hline 1 & Estados Unidos & $1 \%$ & $44 \%$ & 304.82 \\
\hline 2 & Alemania & $-14 \%$ & $8 \%$ & 62.52 \\
\hline 3 & Sudáfrica & $6 \%$ & $7 \%$ & 43.64 \\
\hline 4 & Federación Rusa & $108 \%$ & $6 \%$ & 19.85 \\
\hline 5 & México & $-11 \%$ & $4 \%$ & 33.49 \\
\hline 6 & Polonia & $-20 \%$ & $3 \%$ & 27.7 \\
\hline 7 & China & $-3 \%$ & $3 \%$ & 22.38 \\
\hline 8 & Chile & $38 \%$ & $2 \%$ & 11.7 \\
\hline 9 & Canadá & $33 \%$ & $2 \%$ & 11.85 \\
\hline 10 & India & $-3 \%$ & $2 \%$ & 12.92 \\
\hline 1000 & Otros Paises & $-8 \%$ & $19 \%$ & 142.76 \\
\hline
\end{tabular}

Fuente: COMTRADE 


\subsection{Objetivo General}

Analizar la situación financiera de la compañía EXSA S.A. al 31 de diciembre del 2017 2017, mediante la aplicación de índices o ratios financieros y no financieros, determinar sus posibilidades de crecimiento a través de la proyección de los estados financieros para los años 2018, 2019 y 2020

\subsection{Objetivos Específicos}

Aplicar los índices o ratios financieros y no financieros, teniendo como base los estados financieros auditados separados de los años 2015 - 2016 - 2017 publicados en la página web de la Superintendencia del Mercado de Valores, los cuales son de uso público.

Analizar los resultados obtenidos como consecuencia de la aplicación de los índices o ratios financieros priorizando la evaluación de la situación financiera de EXSA S.A. al 31 de diciembre de 2017. 


\section{CAPITULO III MARCO METODOLÓGICO}

\subsection{Metodología de Recolección de la Información}

El método consistió utilizar los estados financieros separados auditados públicos, descargados de la dirección web de la Bolsa de Valores, considerando los datos más relevantes, tanto actuales como de años anteriores, para poder obtener comparaciones y/o tendencias.

Las fuentes de información utilizadas fueron: Estados financieros separados y públicos que aparecen en la Superintendencia de Mercado de Valores (SMV), Bolsa de Valores de Lima (BVL), Banco Central de Reserva del Perú (BCRP) y libros de apoyo en temas financieros.

Toda la información financiera de la compañía se obtuvo de las SMV y de la BVL, en las cuales se puedo encontrar la siguiente información pública:

- Declaración de Responsabilidad.

- Estados Financieros.

- Notas a los estados Financieros.

- Análisis y discusión de la gerencia.

- Carta informando presentación de la información.

Adicionalmente se hiso uso de tanto de Libro, como de páginas web de revistas y diarios virtuales, entidades supervisoras del estado, reportes económicos de bancos y de bases de datos, con el fin de apoyarme en información actualizada de la empresa y de las interpretaciones tanto de ratios financieros, como en el análisis porcentual de los estados financieros.

Se obtuvo información sobre el WACC en el laboratorio de mercado de capitales de la universidad de lima, considerando que nos permite obtener cuanto le cuesta a la empresa financiarse con capitales propios y con terceros, dicha información nos permitió definir cuál verdadero beneficio económico de la empresa. 


\subsection{Metodología de Análisis de la Información}

Para poder realizar la evaluación financiera es necesario tener claro las actividades y competencias de la compañía, es por ello que no solo se tendrá presente los elementos cualitativos, si no también cuantitativos del sector, la economía y de la misma compañía.

Las técnicas utilizadas para poder elaborar la evaluación financiera son las siguientes:

- Técnica de Análisis Horizontal

Es una técnica en la cual se compara estados financieros homogéneos en varios periodos consecutivos para determinar las variaciones de las cuentas, de un periodo a otro. Este análisis es de gran relevancia, considerando que en él se informa el impacto, negativo o positivo, de los cambios en las actividades y los resultados obtenidos, también permite identificar que partidas merecen mayor atención por tener cambios significativos de un ejercicio a otro.

- Técnica de Análisis Vertical

Es el análisis que establece la relación porcentual que guarda cada componente de los estados financieros respecto a la cifra total, es decir determinar la composición porcentual de cada cuenta de Balance de Situación, considerando como base el Valor del Activo Total y en el caso del estado de resultados cada uno de sus elementos partir de las ventas. Con esta técnica se identifica la importancia e incidencia de cada partida y permite una mejor comprensión, tanto de la estructura como de la comprensión de los estados financieros para cada ejercicio.

- Técnica de Índices o Ratios Financieros

Es una técnica que permite mejorar la comprensión de los estados financieros y la tendencia en el tiempo, generando indicadores clave de desempeño que aportan a visión global necesaria del desempeño de la empresa. 
A continuación, se detallan las ratios que van a analizar y el motivo de su uso.

- Liquidez: permite diagnosticar si una empresa es capaz de generar tesorería, es decir, si tiene capacidad de cumplir con sus obligaciones de corto plazo.

- Endeudamiento: pone de manifiesto la proporción que existe entre la financiación ajena con la que cuenta la empresa y sus recursos propios.

- Actividad: Son ratios que miden la eficiencia en la gestión de cobros, ventas e inventarios, es decir el tiempo que el efectivo de una empresa permanece inmovilizado en sus operaciones, el que estos periodos sea más corto mejoraría la capacidad de obtener utilidades, básicamente porque reduce la necesidad de requerir financiamiento externo, por lo que la compañía cuenta con efectivo o equivalente de efectivo liquido más rápidamente, dinero que no representa para la empresa costo de financiamiento ni gastos innecesarios.

- Rentabilidad: Las ratios de rentabilidad indican si el negocio está rindiendo lo suficiente en relación con los gastos que te demanda y lo invertido. Mientras mayor sea el rendimiento obtenido, la política administrativa adoptada por la compañía nos llevara a una situación financiera solvente y estable. 


\section{CAPITULO IV ANÁLISIS Y PRESENTACIÓN Y DISCUSIÓN DE RESULTADOS}

\subsection{Análisis de la Información}

\subsubsection{Análisis horizontal}

Esta herramienta de análisis financiero consiste en determinar, para dos o más periodos consecutivos, las tendencias de cada una de las cuentas que conforman el Balance General y el Estado de Pérdidas y Ganancias.

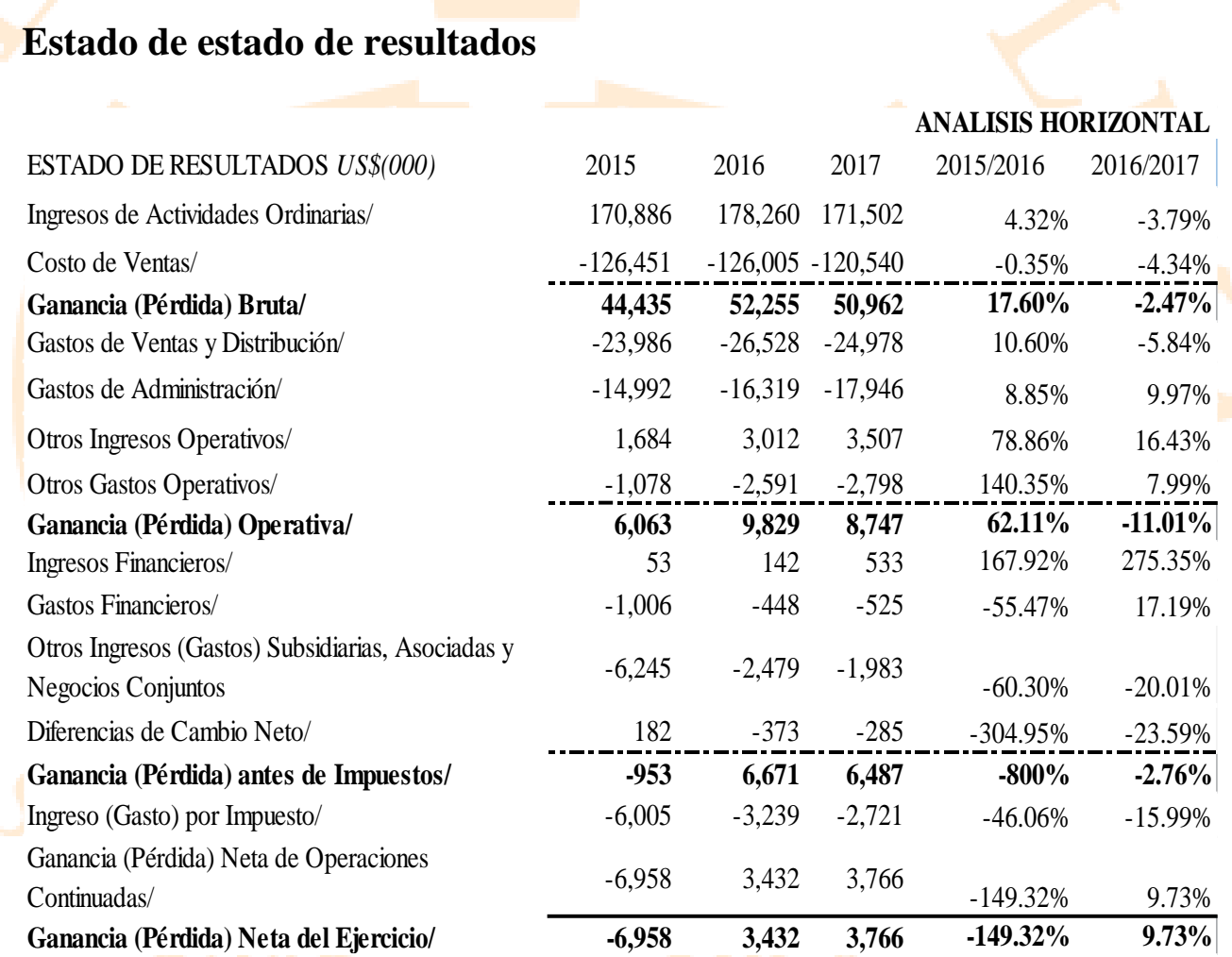

Fuente: Elaboración Propia

A continuación, se efectúan los comentarios de las variaciones más importantes.

Como se observa, los ingresos por actividades ordinarias (ventas) en el comparativo año 2015 a 2016 aumentaron en 4.32\% sustentado principalmente por el aumento de ventas de Dinamitas en el mercado regional y la adjudicación de dos contratos importantes de Tajo Abierto como son Chinalco y Antapaccay. 
A nivel de dólares, el mayor impacto durante el 2016 se debió a los ajustes de precio en el mercado subterráneo, incentivado por la agresiva competencia en este segmento.

Caso contrario si comparamos los resultados por ventas 2016 versus 2017 hubo un decremento del $3.79 \%$, generado por que las exportaciones, se redujeron en $3.6 \%$ con respecto al año 2016, sustentado principalmente por la caída en ventas en Bolivia (dinamitas y emulsión encartuchada). Sin embargo, se incrementaron las ventas a Estados Unidos y se generó la apertura de un nuevo canal de distribución en Bolivia, los cuales ayudaron a reducir el déficit.

A nivel de dólares, el impacto negativo durante el 2017 se debió principalmente a dos factores, 1) a los bajos precios del amoniaco, que afectaron directamente a los precios de los principales agentes de voladura comercializados en el mercado de tajo abierto y 2) a una agresiva competencia de precios en el mercado subterráneo, especialmente en clientes regionales.

Si revisamos la variación del costo de ventas en el año 2016 con respecto a la obtenida en el 2017 podemos apreciar que, a pesar de que en el 2016 se incrementaron las ventas se mantuvo el nivel de costo de ventas con respecto al año 2015, esto ocurrió básicamente porque priorizaron la optimización de los costos de producción, logrando reducir precios de materias primas enfocándose en el $20 \%$ de materiales que representaban el $80 \%$ de los costos y a su vez por que trabajaron con proveedores alternativos, tanto nacionales como extranjeros. Durante el 2017 se mantuvieron la optimización de los costos logísticos de aquellas materias primas consideradas estratégicas por representar el $90 \%$ de los costos, lo cual se ve reflejado en una disminución del costo de venta en $4.34 \%$.

En el caso de la Utilidad Bruta disminuyo en 2.47\% en el comparativo 2016 a 2017, el cual se ve afectado por la disminución de los ingresos por ventas.

Utilidad Neta en el ejercicio 2017 fue de USD 3,766 miles (Tres millones setecientos sesenta y seis mil dólares americanos, la cual representa un incremento del 9.73\% con respecto a lo obtenido en 2016. 
En el caso de la utilidad neta en el ejercicio 2015 tuvo pérdida Neta US\$ 6,958,052 generada por la venta de su operación en Brasil, a un tercero no relacionado (Vendida por US\$70,000,000 cuyo costo neto fue de US\$74,842,000, generando una pérdida neta de US\$4,842,000 en la venta) incluyendo impactos tributarios.

\section{Estado de situación financiera}

\begin{tabular}{|c|c|c|c|c|c|}
\hline \multirow[b]{2}{*}{ ESTADO DE SITUACION FINANCIERA US\$ (000) } & \multirow[b]{2}{*}{2015} & \multirow[b]{2}{*}{2016} & \multirow[b]{2}{*}{2017} & \multicolumn{2}{|c|}{ ANALISIS HORIZONTAL } \\
\hline & & & & $2015 / 2016$ & 2016/2017 \\
\hline \multicolumn{6}{|l|}{ En miles de USD Americanos } \\
\hline Efectivo y Equivalentes al Efectivo/ & 24,645 & 21,322 & 571 & $-13.48 \%$ & $-97.32 \%$ \\
\hline Cuentas por Cobrar Comerciales/ & 31,471 & 39,611 & 28,940 & $25.87 \%$ & $-26.94 \%$ \\
\hline Cuentas por Cobrar a Entidades Relacionadas/ & 2,572 & 1,625 & 1,835 & $-36.82 \%$ & $12.92 \%$ \\
\hline Otras Cuentas por Cobrar/ & 1,235 & 2,300 & 2,206 & $86.23 \%$ & $-4.09 \%$ \\
\hline Inventarios/ & 42,562 & 41,022 & 40,018 & $-3.62 \%$ & $-2.45 \%$ \\
\hline Gastos Pagados por Anticipado & 810 & 1,511 & 1,216 & $86.54 \%$ & $-19.52 \%$ \\
\hline $\begin{array}{l}\text { Total Activos Corrientes/ } \\
\text { Activos No Corrientes/ }\end{array}$ & 103,295 & 107,391 & 74,786 & $3.97 \%$ & $-30.36 \%$ \\
\hline $\begin{array}{l}\text { Inversiones en Subsidiarias, Negocios Conjuntos y } \\
\text { Asociadas/ }\end{array}$ & 530 & 481 & 272 & $-9.25 \%$ & $-43.45 \%$ \\
\hline Cuentas por Cobrar a Entidades Relacionadas/ & 0 & 2,100 & 13483 & & $542.05 \%$ \\
\hline Propiedades, Planta y Equipo/ & 56,416 & 82,002 & 94872 & $45.35 \%$ & $15.69 \%$ \\
\hline Activos Intangibles Distintos de la Plusvalía/ & 1,319 & 1,671 & 1246 & $26.69 \%$ & $-25.43 \%$ \\
\hline Activos por Impuestos Diferidos/ & 0 & 0 & 0 & & \\
\hline Plusvalía/ & 774 & 774 & 774 & $0.00 \%$ & $0.00 \%$ \\
\hline Otros Activos no Financieros/ & 18 & 18 & 17 & $0.00 \%$ & $-5.56 \%$ \\
\hline Total Activos No Corrientes/ & $\mathbf{5 9 , 0 5 7}$ & 87,046 & 110,664 & $47 \%$ & $27 \%$ \\
\hline \multicolumn{6}{|l|}{$\begin{array}{l}\text { Pasivos y Patrimonio/ } \\
\text { Pasivos Corrientes/ }\end{array}$} \\
\hline Otros Pasivos Financieros/ & 23,000 & 26,200 & 13,570 & $13.91 \%$ & $-48.21 \%$ \\
\hline Cuentas por Pagar Comerciales/ & 11,733 & 23,377 & 14011 & $99.24 \%$ & $-40.07 \%$ \\
\hline Cuentas por Pagar a Entidades Relacionadas/ & 364 & 1,310 & 849 & $259.89 \%$ & $-35.19 \%$ \\
\hline Otras Cuentas por Pagar/ & 8,514 & 8,262 & 10997 & $-2.96 \%$ & $33.10 \%$ \\
\hline Ingresos Diferidos/ & 586 & 620 & 1008 & $5.80 \%$ & $62.58 \%$ \\
\hline $\begin{array}{l}\text { Total Pasivos Corrientes/ } \\
\text { Pasivos No Corrientes/ }\end{array}$ & 44,197 & 59,769 & 40,435 & $35.23 \%$ & $-32.35 \%$ \\
\hline Otros Pasivos Financieros/ & 8,787 & 22,697 & 29,338 & $158.30 \%$ & $29.26 \%$ \\
\hline Cuentas por Pagar Comerciales y Otras Cuentas por Pagar/ & 0 & 5 & 0 & & $-100.00 \%$ \\
\hline Pasivos por Impuestos Diferidos/ & 1,351 & 499? & 441 & $-63.06 \%$ & $-11.62 \%$ \\
\hline Total Pasivos No Corrientes/ & 10,138 & 23,201 & 29,779 & $128.85 \%$ & $28.35 \%$ \\
\hline \multicolumn{5}{|l|}{ Patrimonio/ } & $-15.37 \%$ \\
\hline Capital Emitido/ & 37,066 & 37,066 & 37,066 & $0.00 \%$ & $0.00 \%$ \\
\hline Acciones de Inversión/ & 18,533 & 18,533 & 18,533 & $0.00 \%$ & $0.00 \%$ \\
\hline Otras Reservas de Capital & 8,997 & 8,997 & 8,997 & $0.00 \%$ & $0.00 \%$ \\
\hline Resultados Acumulados/ & 36,854 & 40,286 & 44,052 & $9.31 \%$ & $9.35 \%$ \\
\hline Otras Reservas de Patrimonio/ & 6,567 & 6,585 & 6,588 & $.0 .27 \%$ & $0.05 \%$ \\
\hline Total Patrimonio/ & 108,017 & 111,467 & 115,236 & $3.19 \%$ & $3.38 \%$ \\
\hline TOTAL PASIVOS Y PAT & 162,352 & 194,437 & 185,450 & $19.76 \%$ & $-4.62 \%$ \\
\hline
\end{tabular}

Fuente: Elaboración Propia

A continuación, se efectúan los comentarios de las variaciones más importantes. 
Con respecto a los activos: La variación del efectivo y equivalente de efectivo fue generada por la disminución de los fondos disponibles, la cual está representada principalmente por la utilización de efectivo para las actividades de financiamiento y de inversión. En el caso de las cuentas corrientes se mantienen en bancos locales y están denominadas en soles y dólares estadounidenses, no generan intereses, ni tienen restricciones de disposición (préstamos otorgados a subsidiarias y pago de obligaciones financieras).

En el caso de las cuentas por cobrar lograron un mejor desempeño en el 2017 con respecto a reducir tanto la deuda no deteriorada como la deteriorada en un $26.94 \%$ en comparación al 2016.

Con respecto a las cuentas por cobrar a entidades relacionadas, el incremento de dichas partidas al 31 de diciembre de 2017 y de 2016, son generadas por que la Compañía ha otorgado préstamos a su subsidiaria Exsa Chile Spa S.A. para capital de trabajo y la construcción de su planta en Antofagasta; el cual tiene un vencimiento hasta el 2021 y concede un periodo de gracia hasta el 2018. Dichos préstamos generan intereses a una tasa de interés anual del orden del 6.5. Durante el año 2017, dichos préstamos generaron intereses por US\$449,00.

En el caso de la propiedad, planta y equipo, el principal incremento durante los años 2017 y 2016 corresponde al desarrollo de la Planta de iniciación de explosivos (Proyecto Nazca), la cual ha demandado desembolsos por aproximadamente US $\$ 13,133,000$ y US $\$ 21,645,000$, respectivamente. Una parte del proyecto se adquirió mediante contrato de arrendamiento financiero por un importe ascendente a US\$6,726,000 y US\$11,399,000, respectivamente. Asimismo, incluye la capitalización de los intereses devengados de los arrendamientos financieros adquiridos para el desarrollo de este proyecto por US\$847,000 y US\$551,000, respectivamente.

Con respecto a Inversiones en Subsidiarias, Negocios conjuntos y asociadas, la variación en el año 2017, corresponde a los aportes realizados a Exsa Colombia por US $\$ 238,000$ y a International Blasting Services por US\$10,000; mientras que en el año 2016 corresponde a los aportes Exsa Colombia por US\$536,000, respectivamente. 
En relación a los Pasivos, podemos indicar: Con respecto a las cuentas por pagar comerciales, disminuyeron en el 2017, con respecto al 2016, en un $40 \%$ específicamente por que las facturas por pagar al extranjero disminuyeron considerablemente, entendemos que han sido pagadas. Dichas cuentas por pagar comerciales se originan, principalmente, por las adquisiciones de materia prima y de mercadería comercializada por la compañía.

En el caso de la variación de las otras cuentas por pagar, han aumentado en el 2017 respecto al 2016, dicho incremento corresponde principalmente a la provisión por avance de obra de la construcción realizada por Heap Leaching S.A. en el Proyecto Nazca.

En el caso de Otros pasivos financieros, los incrementos durante los años 2016 y 2017 atienden a arrendamientos financieros (Leasing) fueron utilizados para la construcción, compra de equipos y otros bienes relacionados con el Proyecto Nazca, al 31 de diciembre de 2017 el leasing aún se encuentra en estado abierta y se espera que al término del proyecto (abril 2018) se defina los plazos y montos de las cuotas a pagar por esta obligación.

\subsubsection{Análisis vertical}

\section{Estado de estado de resultados}

ESTADO DE RESULTADOS US\$(000)
Ingresos de Actividades Ordinarias/
Costo de Ventas/
Ganancia (Pérdida) Bruta/
Gastos de Ventas y Distribución/
Gastos de Administración/
Otros Ingresos Operativos/
Otros Gastos Operativos/
Ganancia (Pérdida) Operativa/
Ingresos Financieros/
Gastos Financieros/
Otros Ingresos (Gastos) Subsidiarias, Asociadas y
Negocios Conjuntos
Diferencias de Cambio Neto/
Ganancia (Pérdida) antes de Impuestos/
Ingreso (Gasto) por Impuesto/
Ganancia (Pérdida) Neta de Operaciones
Continuadas/
Ganancia (Pérdida) Neta del Ejercicio/

\begin{tabular}{|c|c|c|c|c|c|}
\hline & \multicolumn{5}{|c|}{ ANALISIS VERTICAL } \\
\hline 2015 & 2016 & 2017 & 2015 & 2016 & 2017 \\
\hline 170,886 & 178,260 & 171,502 & $100.00 \%$ & $100.00 \%$ & $100.00 \%$ \\
\hline$-126,451$ & $-126,005$ & $-120,540$ & $74.00 \%$ & $70.69 \%$ & $70.28 \%$ \\
\hline 44,435 & 52,255 & 50,962 & $26.00 \%$ & $29.31 \%$ & $29.72 \%$ \\
\hline$-23,986$ & $-26,528$ & $-24,978$ & $14.04 \%$ & $14.88 \%$ & $14.56 \%$ \\
\hline$-14,992$ & $-16,319$ & $-17,946$ & $8.77 \%$ & $9.15 \%$ & $10.46 \%$ \\
\hline 1,684 & 3,012 & $3,507^{\prime}$ & $0.99 \%$ & $1.69 \%$ & $2.04 \%$ \\
\hline$-1,078$ & $-2,591$ & $-2,798$ & $0.63 \%$ & $1.45 \%$ & $1.63 \%$ \\
\hline 6,063 & 9,829 & 8,747 & $3.55 \%$ & $5.51 \%$ & $5.10 \%$ \\
\hline 53 & 142 & 533 & $0.03 \%$ & $0.08 \%$ & $0.31 \%$ \\
\hline$-1,006$ & -448 & -525 & $0.59 \%$ & $0.25 \%$ & $0.31 \%$ \\
\hline$-6,245$ & $-2,479$ & $-1,983$ & $3.65 \%$ & $1.39 \%$ & $1.16 \%$ \\
\hline 182 & -373 & $-285^{\prime}$ & $0.11 \%$ & $-0.21 \%$ & $-0.17 \%$ \\
\hline-953 & 6,671 & 6,487 & $0.56 \%$ & $3.74 \%$ & $3.78 \%$ \\
\hline$-6,005$ & $-3,239$ & $-2,721$ & $3.51 \%$ & $1.82 \%$ & $1.59 \%$ \\
\hline$-6,958$ & 3,432 & 3,766 & $4.07 \%$ & $1.93 \%$ & $2.20 \%$ \\
\hline 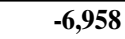 & 3,432 & 66 & $-4.07 \%$ & $1.93 \%$ & $2.20 \%$ \\
\hline
\end{tabular}

Fuente: Elaboración Propia 
A continuación, se efectúan los comentarios de las variaciones más importantes.

El 2016 el costo de venta represento el $71 \%$ de las ventas netas, esto se debe principalmente a la mayor composición de ventas de productos destinados al mercado de tajo abierto, igual que en el ejercicio anterior, el cual a diferencia del 2016 fue del $74 \%$ de las ventas (2015) y para el 2017 fue de $70 \%$.

Para el 2015 el total de los Gastos Administrativos, de Ventas, Financieros y otros representaron el 26\% de las Ventas Netas, similar al porcentaje del 2016 y 2017.

El resultado Neto del ejercicio durante el 2017 ha sido mejor que el del 2016 (3.973\%) a pesar de que las ventas fueron menores que las obtenidas en 2016 (-3.79\%) sin embargo podemos notar que el resultado en relación a la venta tiene una mayor proporción en el 2017 (2.20\%) dicha mejoría es el efecto de los mayores ingresos financieros, los cuales provienen de los intereses por los préstamos otorgados a las empresas relacionadas en relación (EXSA Chile SPA S.A. para capital de trabajo). 


\section{Estado de situación financiera}

\begin{tabular}{|c|c|c|c|c|c|c|}
\hline \multirow[b]{2}{*}{ ESTADO DE SITUACION FINANCIERA US\$ (000) } & \multirow[b]{2}{*}{2015} & \multirow[b]{2}{*}{2016} & \multirow[b]{2}{*}{2017} & \multicolumn{3}{|c|}{ ANALISIS VERTICAL } \\
\hline & & & & 2015 & 2016 & 2017 \\
\hline \multicolumn{7}{|l|}{ En miles de USD Americanos } \\
\hline Efectivo y Equivalentes al Efectivo/ & 24,645 & 21,322 & 571 & $15.18 \%$ & $10.97 \%$ & $0.31 \%$ \\
\hline Cuentas por Cobrar Comerciales/ & 31,471 & 39,611 & 28,940 & $19.38 \%$ & $20.37 \%$ & $15.61 \%$ \\
\hline Cuentas por Cobrar a Entidades Relacionadas/ & 2,572 & 1,625 & 1,835 & $1.58 \%$ & $0.84 \%$ & $0.99 \%$ \\
\hline Otras Cuentas por Cobrar/ & 1,235 & 2,300 & 2,206 & $0.76 \%$ & $1.18 \%$ & $1.19 \%$ \\
\hline Inventarios/ & 42,562 & 41,022 & 40,018 & $26.22 \%$ & $21.10 \%$ & $21.58 \%$ \\
\hline Gastos Pagados por Anticipado & 810 & 1,511 & 1,216 & $0.50 \%$ & $0.78 \%$ & $0.66 \%$ \\
\hline $\begin{array}{l}\text { Total Activos Corrientes/ } \\
\text { Activos No Corrientes/ }\end{array}$ & 103,295 & 107,391 & 74,786 & $64 \%$ & $55 \%$ & $40 \%$ \\
\hline $\begin{array}{l}\text { Inversiones en Subsidiarias, Negocios Conjuntos y } \\
\text { Asociadas/ }\end{array}$ & 530 & 481 & 272 & $0.33 \%$ & $0.25 \%$ & $0.15 \%$ \\
\hline Cuentas por Cobrar a Entidades Relacionadas/ & 0 & 2,100 & 13483 & $0.00 \%$ & $1.08 \%$ & $7.27 \%$ \\
\hline Propiedades, Planta y Equipo/ & 56,416 & 82,002 & 94872 & $34.75 \%$ & $42.17 \%$ & $51.16 \%$ \\
\hline Activos Intangibles Distintos de la Plusvalía/ & 1,319 & 1,671 & 1246 & $0.81 \%$ & $0.86 \%$ & $0.67 \%$ \\
\hline Activos por Impuestos Diferidos/ & 0 & 0 & 0 & $0.00 \%$ & $0.00 \%$ & $0.00 \%$ \\
\hline Plusvalía/ & 774 & 774 & 774 & $0.48 \%$ & $0.40 \%$ & $0.42 \%$ \\
\hline Otros Activos no Financieros/ & 18 & 18 & 17 & $0.01 \%$ & $0.01 \%$ & $0.01 \%$ \\
\hline Total Activos No Corrientes/ & $\mathbf{5 9 , 0 5 7}$ & 87,046 & 110,664 & $36 \%$ & $45 \%$ & $60 \%$ \\
\hline $\begin{array}{l}\text { TOTAL ACTIVOS/ } \\
\text { Pasivos y Patrimonio/ } \\
\text { Pasivos Corrientes/ }\end{array}$ & 162,352 & 194,437 & 185,450 & $100 \%$ & $100 \%$ & $100 \%$ \\
\hline Otros Pasivos Financieros/ & 23,000 & 26,200 & 13,570 & $14.17 \%$ & $13.47 \%$ & $7.32 \%$ \\
\hline Cuentas por Pagar Comerciales/ & 11,733 & 23,377 & 14011 & $7.23 \%$ & $12.02 \%$ & $7.56 \%$ \\
\hline Cuentas por Pagar a Entidades Relacionadas/ & 364 & 1,310 & 849 & $0.22 \%$ & $0.67 \%$ & $0.46 \%$ \\
\hline Otras Cuentas por Pagar/ & 8,514 & 8,262 & 10997 & $5.24 \%$ & $4.25 \%$ & $5.93 \%$ \\
\hline Ingresos Diferidos/ & 586 & 620 & 1008 & $0.36 \%$ & $0.32 \%$ & $0.54 \%$ \\
\hline $\begin{array}{l}\text { Total Pasivos Corrientes/ } \\
\text { Pasivos No Corrientes/ }\end{array}$ & 44,197 & 59,769 & 40,435 & $27.22 \%$ & $30.74 \%$ & $21.80 \%$ \\
\hline Otros Pasivos Financieros/ & 8,787 & 22,697 & 29,338 & $5.41 \%$ & $11.67 \%$ & $15.82 \%$ \\
\hline Cuentas por Pagar Comerciales y Otras Cuentas por Pagar/ & 0 & 5 & 0 & $0.00 \%$ & $0.00 \%$ & $0.00 \%$ \\
\hline Pasivos por Impuestos Diferidos/ & 1,351 & 499. & 441 & $\underline{0.83 \%}$ & $0.26 \%$ & $0.24 \%$ \\
\hline Total Pasivos No Corrientes/ & 10,138 & 23,201 & 29,779 & $6.24 \%$ & $11.93 \%$ & $16.06 \%$ \\
\hline $\begin{array}{l}\text { Total Pasivos/ } \\
\text { Patrimonio/ }\end{array}$ & 54,335 & 82,970 & 70,214 & $33.47 \%$ & $42.67 \%$ & $37.86 \%$ \\
\hline Capital Emitido/ & 37,066 & 37,066 & 37,066 & $22.83 \%$ & $19.06 \%$ & $19.99 \%$ \\
\hline Acciones de Inversión/ & 18,533 & 18,533 & 18,533 & $11.42 \%$ & $9.53 \%$ & $9.99 \%$ \\
\hline Otras Reservas de Capital/ & 8,997 & 8,997 & 8,997 & $5.54 \%$ & $4.63 \%$ & $4.85 \%$ \\
\hline Resultados Acumulados/ & 36,854 & 40,286 & 44,052 & $22.70 \%$ & $20.72 \%$ & $23.75 \%$ \\
\hline Otras Reservas de Patrimonio/ & 6,567 & 6,585 & 6,588 & $4.04 \%$ & $3.39 \%$ & $3.55 \%$ \\
\hline Total Patrimonio/ & 108,017 & 111,467 & 115,236 & $66.53 \%$ & $57.33 \%$ & $62.14 \%$ \\
\hline TOTAL PASIVOS Y PATRIMONIO/ & 162,352 & 194,437 & 185,450 & $100.00 \%$ & $100.00 \%$ & $100.00 \%$ \\
\hline
\end{tabular}

Fuente: Elaboración Propia

A continuación, se efectúan los comentarios de las variaciones más importantes.

Analizando el año 2017, la inversión de la empresa se concentra principalmente en los activos no corrientes, dentro de los cuales la cuenta de mayor importancia se encuentra en Propiedad, Planta y Equipos con 51.16\%, considerando que, durante los años 2017 y 2016, la principal adición corresponde al desarrollo de la planta de 
iniciación de explosivos (PROYECTO NAZCA) la cual ha demandado desembolsos por aproximadamente US\$13,133,000 y US\$21,645,000, respectivamente.

Otra cuenta representativa dentro de los activos no corrientes es las cuentas por cobrar a entidades relacionadas con un $7.27 \%$ de equivalencia respecto al total de los activos, la cual básicamente es la que mantiene con EXSA Chile, subsidiaria de EXSA S.A. la cual es por un préstamo para capital de trabajo y la construcción de la planta en Antofagasta; el cual tiene un vencimiento hasta el 2021y concede un periodo de gracia hasta el 2018. Dichos prestamos generan intereses a una tasa anual de $6.5 \%$.

La variación más representativa (baja) en el activo corriente en el año 2017 fue en el efectivo y equivalente de efectivo, el cual solo representa el $0.31 \%$ del total de activos de la empresa, dicha reducción se origina por la disminución de los fondos disponibles representada principalmente por la utilización de efectivo para las actividades de financiamiento e inversión. En el 2017 las inversiones de capital ascendieron a USD 26,593,000, destacando las inversiones para el proyecto de la nueva planta de sistemas de iniciación, así como adquisición de camiones-fabrica, entre otros.

En el 2017, la inversión de la empresa se financia con un $62.14 \%$ con fondos de inversionistas y un $37.86 \%$ con fondos de terceros, donde las cuentas más representativas son las cuentas por pagar corrientes comerciales, la cual se origina por la adquisición de materia prima y de la mercadería comercializada por la compañía y las otras cuentas por pagar corresponde principalmente a la provisión por avance de obra de la construcción realizada por Heap leaching S.A. en el Proyecto Nazca. 


\subsubsection{Análisis ratios financieros}

\section{Liquidez}

Figura 4. 1 Ratio Corriente

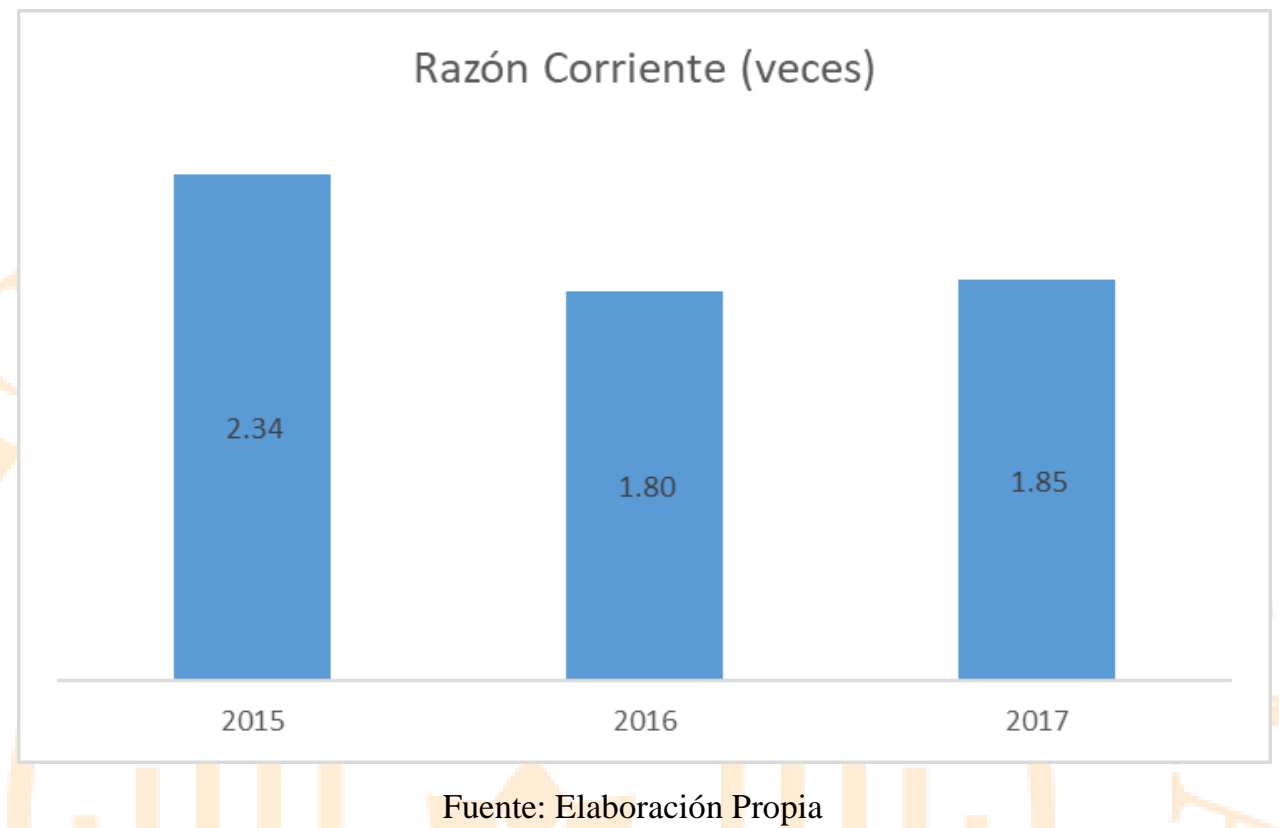

Como podemos ver la empresa mantiene su capacidad para cumplir sus obligaciones inmediatas (incluido inventarios) sin embargo notamos que en el comparativo de la capacidad de la empresa en afrontar sus obligaciones corrientes (pasivos corrientes) con activos corrientes disminuye en el año 2016 versus el 2015, dicha variación se origina básicamente por el incremento en sus cuentas por pagar en 2016, tanto nacionales $(+44 \%)$ como internacionales $(+62 \%)$ originadas por las adquisiciones de materia prima y de mercadería comercializada por la compañía.

Comparando el resultado de la ratio corriente, podemos detectar que para el año 2017 se incrementó en 0.05 con respecto al resultado del 2016, dicho incremento se generó por la disminución de las cuentas por pagar comerciales y las de otros pasivos financieros (pago de préstamos bancarios). Así mismo tanto el efectivo y las cuentas por cobrar del año 2017 con las del 2016 disminuyeron, básicamente por la utilización de los fondos en las actividades de financiamiento e inversión. 
Figura 4. 2 Ratio de Prueba Acida

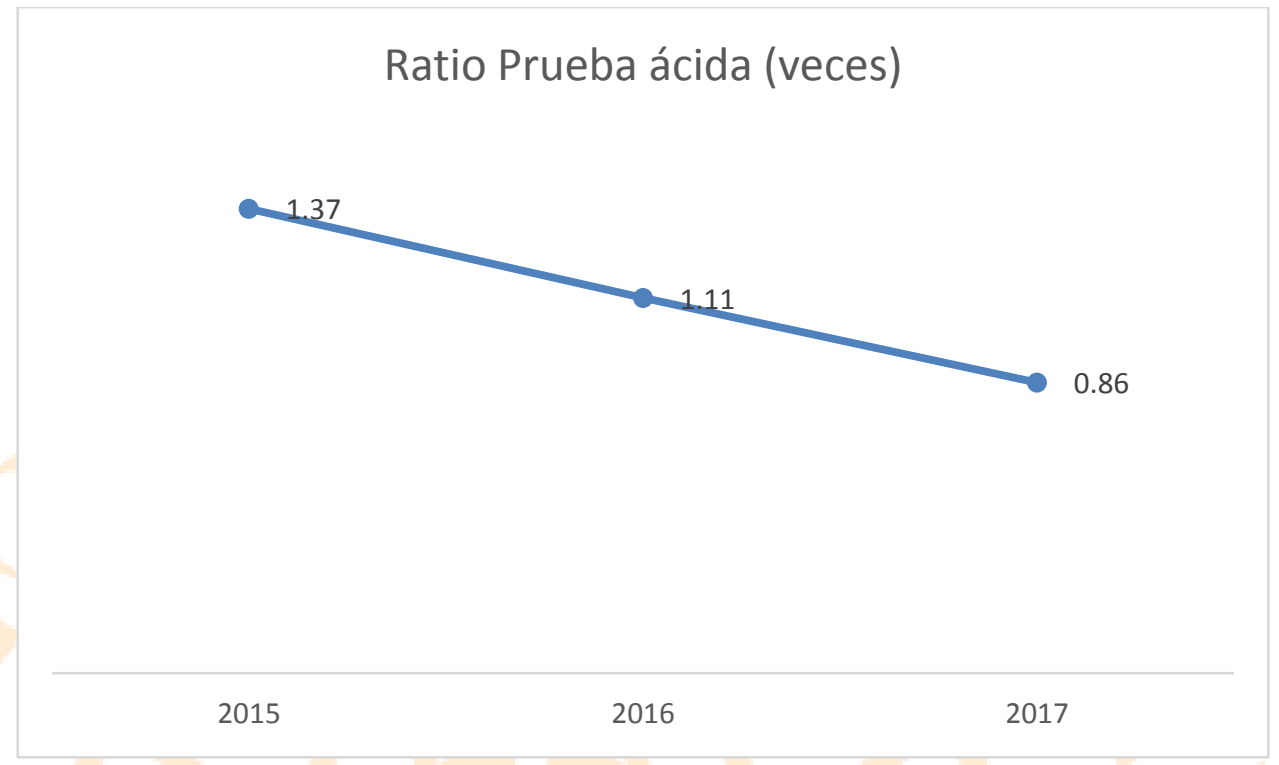

Fuente: Elaboración Propia

Durante el año 2015 al 2016 mantuvieron la capacidad de afrontar sus obligaciones con activos corrientes, sin considerar los inventarios (elemento menos liquido de los activos circulantes) para el 2017 no cubre el 100\% de sus obligaciones a corto plazo sin vender los productos, solo el $86 \%$, es decir pierde la capacidad que años atrás tuvo.

Figura 4. 3 Ratio de Capital de Trabajo

$$
\text { Capital de trabajo (USD 000) }
$$


El capital de trabajo es fundamental para toda empresa, porque nos muestra el manejo financiero de la empresa a corto plazo, en el caso de la empresa EXSA podemos ver que el resultado es positivo y constante durante los años revisados.

Podemos notar que, si bien durante los 3 años el capital de trabajo ha ido disminuyendo, es básicamente porque la empresa utilizo fondos disponibles en actividades de financiamiento y de inversión (Préstamos otorgados a EXSA Chile para Capital de trabajo, el desarrollo de la planta iniciación de explosivos Proyecto NAZCA y aportes realizados a EXSA Colombia e International Blasting Service).

\section{Endeudamiento}

Figura 4. 4 Ratio de Grado de Propiedad

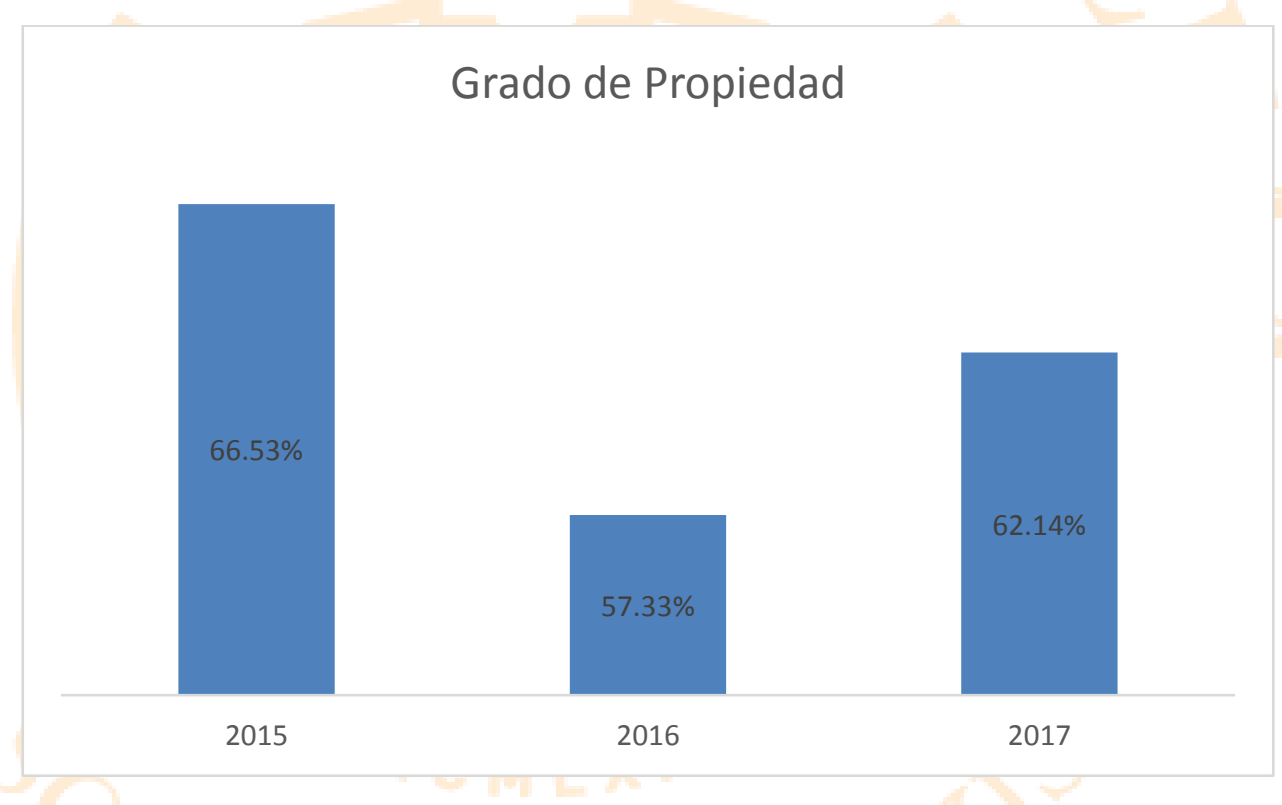

Fuente: Elaboración Propia

Se puede apreciar que para el 2017, por cada USD 61 de financiación ajena (Pasivo) la empresa cuenta con USD 100 financiamiento propio, lo cual indica que EXSA cuenta con suficiente independencia financiera (dentro de lo óptimo) actualmente la empresa tiene préstamos bancarios por un total USD 51,773 (000) correspondiente a inversiones a el proyecto de la nueva planta de sistemas de iniciación, así como adquisición de camiones-fábrica, entre otros. 
Figura 4. 5 Ratio de Endeudamiento

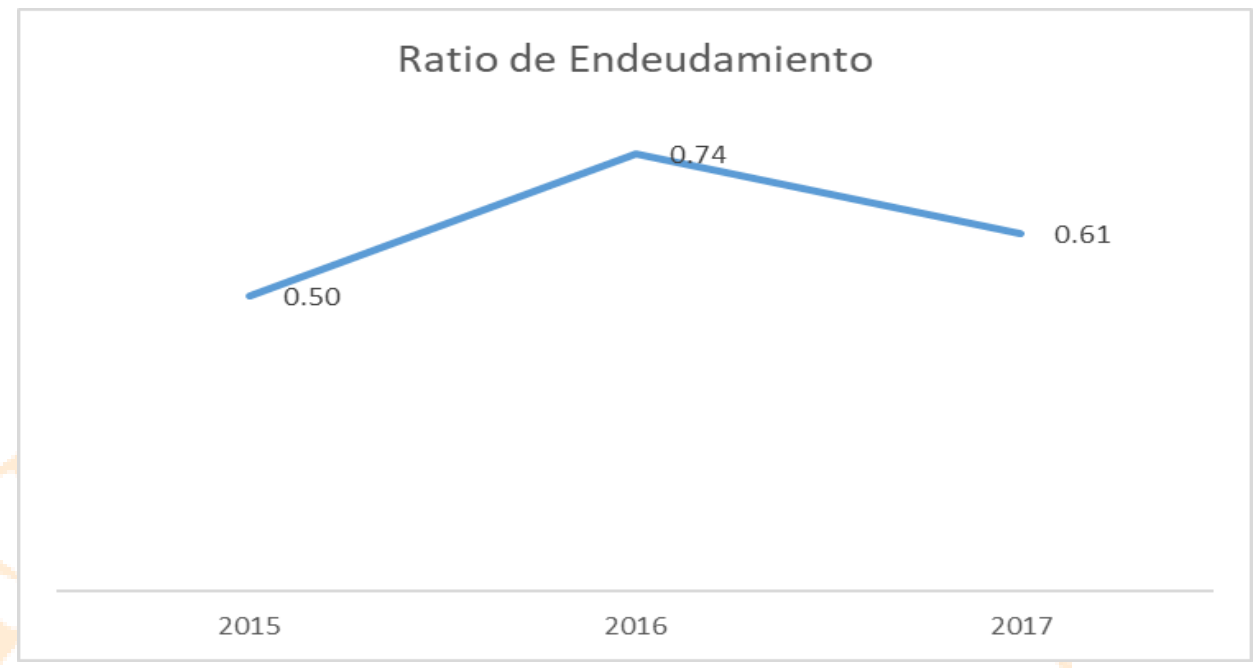

Fuente: Elaboración Propia

La intensidad de la deuda comparada con los fondos de financiamiento propios no es constante en los 3 años analizados, es decir entre 0.5 a 0.61 , sin embargo, podemos deducir el grado de influencia de los terceros en el funcionamiento y equilibrio financiero permanente de la empresa. Cuanto menor es la ratio más autónoma es la empresa, es decir indica que tan apalancada se encuentra la empresa mediante financiación ajena, tanto a largo como a corto plazo en relación a sus fondos propios.

\section{Actividad}

Figura 4. 6 Periodo Promedio de Cobro

$$
\text { Periodo Promedio de cobro (Días) }
$$

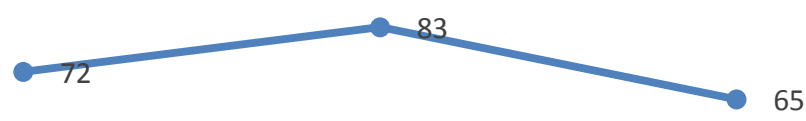


Con respecto a los días que la empresa tarda en cobrar a sus clientes, en el 2017 la empresa tuvo un periodo promedio de cobro de menos 18 días en comparación con el año 2016 y menos 7 días con respecto al 2015, es decir que la empresa está siendo más eficiente en el uso de sus activos corrientes (cuentas por cobrar) para generar ventas.

Figura 4. 7 Periodo Promedio de Inventarios
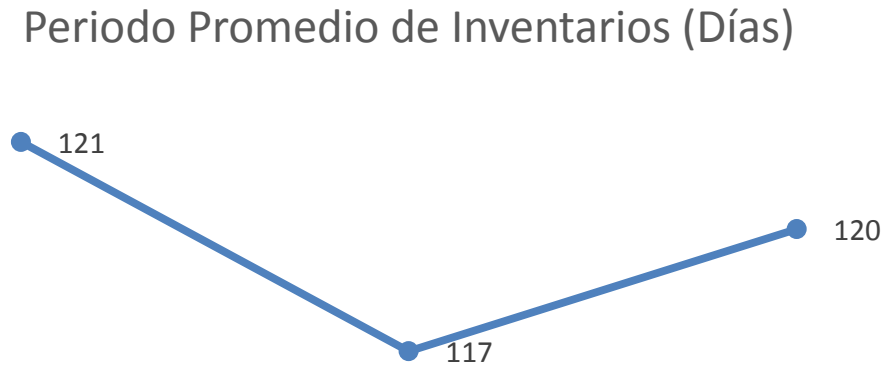

2015

2016

2017

Fuente: Elaboración Propia

Si bien comparamos el periodo promedio de inventario del año 2016 con el obtenido en el 2015, es claro que mejoro 4 días, sin embargo, en el año 2017 los inventarios tuvieron un movimiento más lento que en 2016, es decir la mercadería tardo en venderse 3 días adicionales que en el año anterior.

Figura 4. 8 Periodo Promedio de Cuentas por Pagar

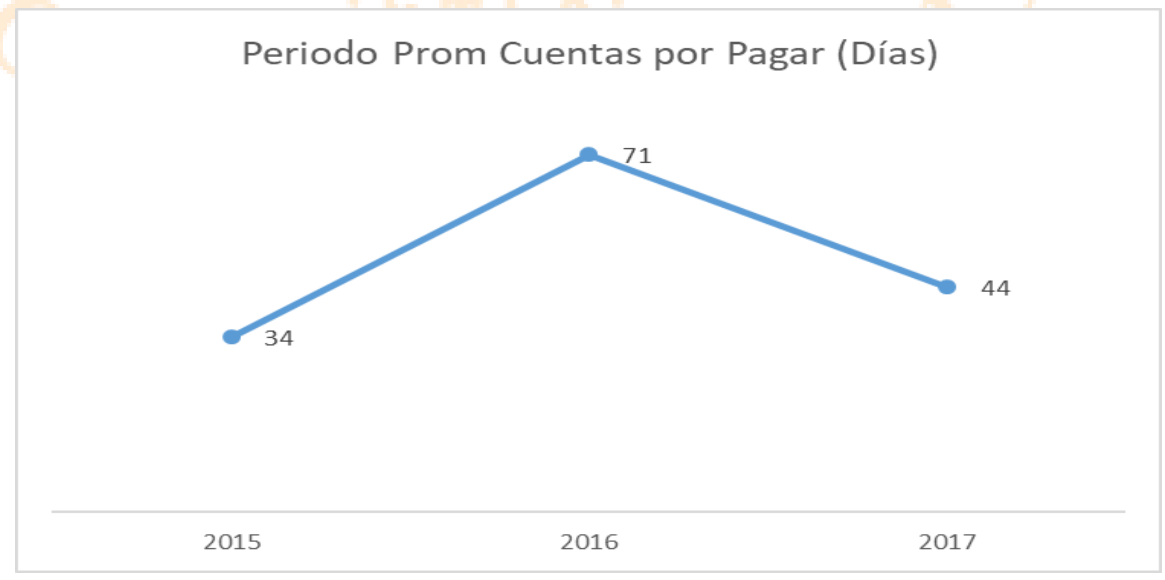

Fuente: Elaboración Propia 
En el caso de le periodo promedio de cuentas por pagar, si comparamos el resultado del 2016 versus 2015 se incrementó en 37 días, es decir aumento los días que se demora en pagar a sus proveedores mediante la erogación de efectivo, debido al impacto en la disminución de sus ventas y por ellos sus pagos por obligaciones operativas fueron menores comparados con el 2015, así mismo los días de demora en la cobranza se incrementaron en 9 días y el ingreso de efectivo por dichos cobros fueron menores en el 2016.

Caso contrario fue en el 2017, en el cual la empresa se demoró en cobrar en menos días que en 2016 (-18 días) lo cual tiene concordancia con el incremento de la cobranza a clientes y terceros en más del 7\% con respecto al 2016.y demoró menos efectuar sus pagos a proveedores, con respecto al 2016 (-27 días) es por ello que el importe de sus pagos fue mayor que en el 2016.

Figura 4. 9 Ciclo de Conversión

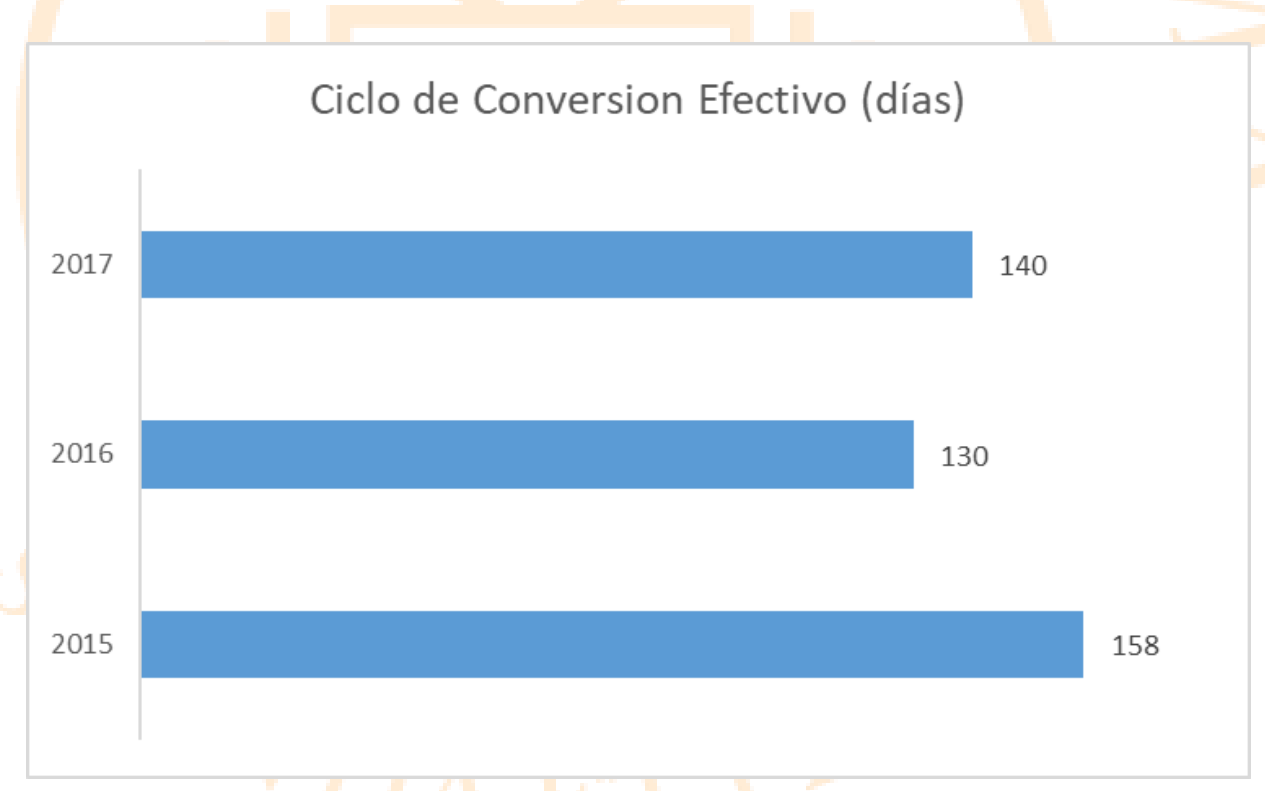

Fuente: Elaboración Propia

Se puede visualizar que para el 2017 el Ciclo de conversión de efectivo (CCE) se ha incrementado en 10 días con respecto al año anterior, aumentado el tiempo que transcurre desde que se paga la compra de materia prima necesaria para manufacturar el producto hasta la cobranza por la venta de dicho producto, es decir están siendo menos eficientes. Si comparamos el resultado del CCE del 2017 con respecto al 2015 podemos detectar una disminución de 18 días. 
Debemos de considerar que la empresa con el fin de disminuir el CCE debe de incorporar medidas que hagan que los días de cobranza sean menores (estrategias de cobranza) que los días de inventario se reduzcan, sin afectar la calidad del producto y que se mantenga un estatus en el cual primero se cobre y después se pueda pagar las obligaciones con proveedores y terceros sin problemas.

\section{Rentabilidad}

Figura 4. 10 Rentabilidad Sobre el Patrimonio (ROE)

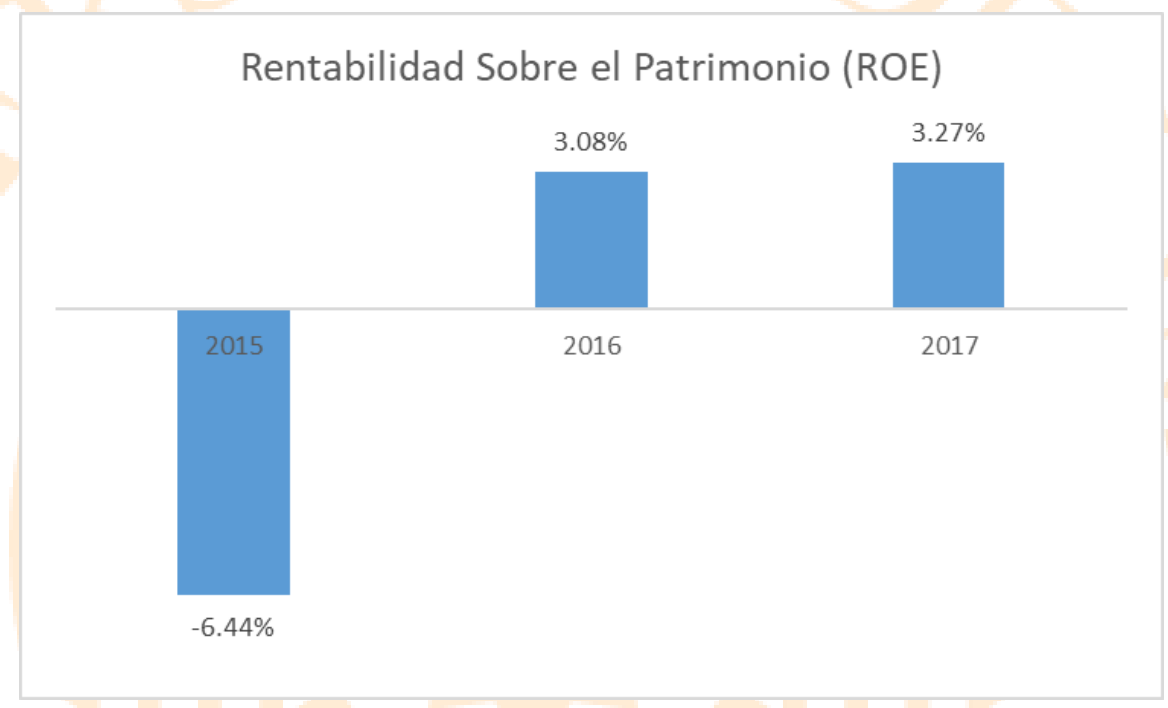

Fuente: Elaboración Propia

En el año 2015 el indicador de rentabilidad sobre el patrimonio se ve seriamente afectado por el resultado (Utilidad Neta negativa) como consecuencia de la pérdida neta obtenida en el mismo año, dicho resultado incluye la pérdida contable generada por la venta de su operación en Brasil, a un tercero no relacionado (Vendida por US\$70,000,000 cuyo costo neto fue de US\$74,842,000, generando una pérdida neta de US\$4,842,000 en la venta) es decir la Junta General de accionistas, en mayo 2015, decidió enajenar el 100\% de su participación en la empresa XION I PARTICIPAÇÕES S.A., empresa brasilera.

Durante el año 2016 y 2017 podemos notar que el resultado es positivo y se mantiene de forma positiva, lo cual quiere decir que para el 2017 la empresa ha generado beneficio económico $3.27 \%$ con respecto al exclusivo aporte de los dueños (ROE). 
Figura 4. 11 Rentabilidad Sobre los Activos (ROA)

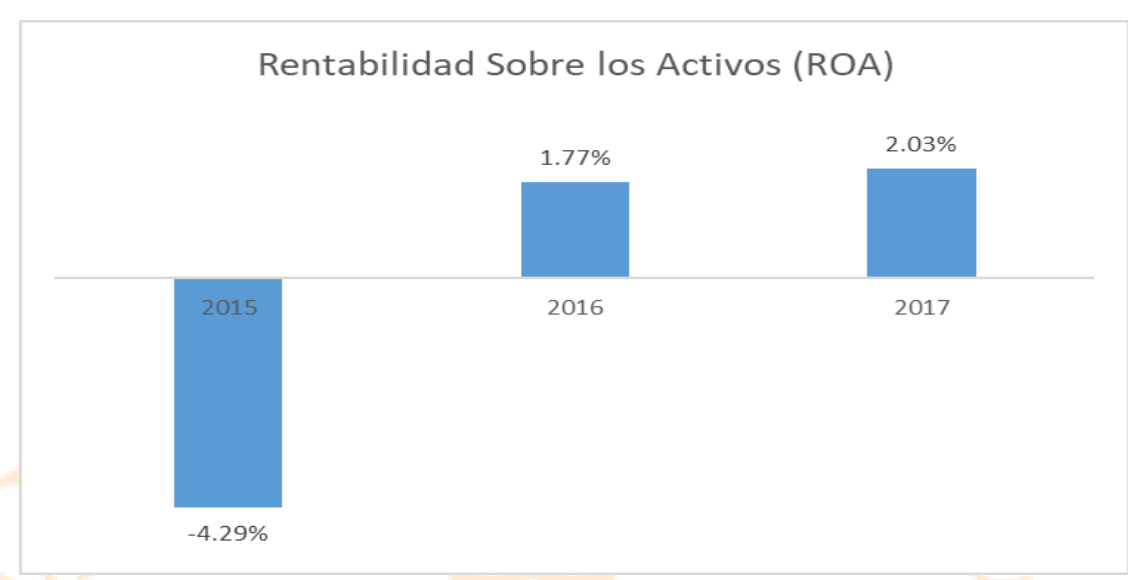

Fuente: Elaboración Propia

En el año 2015 el indicador de rentabilidad sobre los activos se ve seriamente afectado por el resultado (Utilidad Neta negativa) como consecuencia de la pérdida neta obtenida en el mismo año (Venta del 100\% de su participación en la empresa XION I PARTICIPAÇÕES S.A., empresa brasilera) es claro que en 2017 hubo un incremento con relación al 2016, del total de recursos que la empresa posee contribuye $2.03 \%$ en la generación de beneficio económico (ROA).

Figura 4. 12 Rentabilidad de Ventas (ROS)

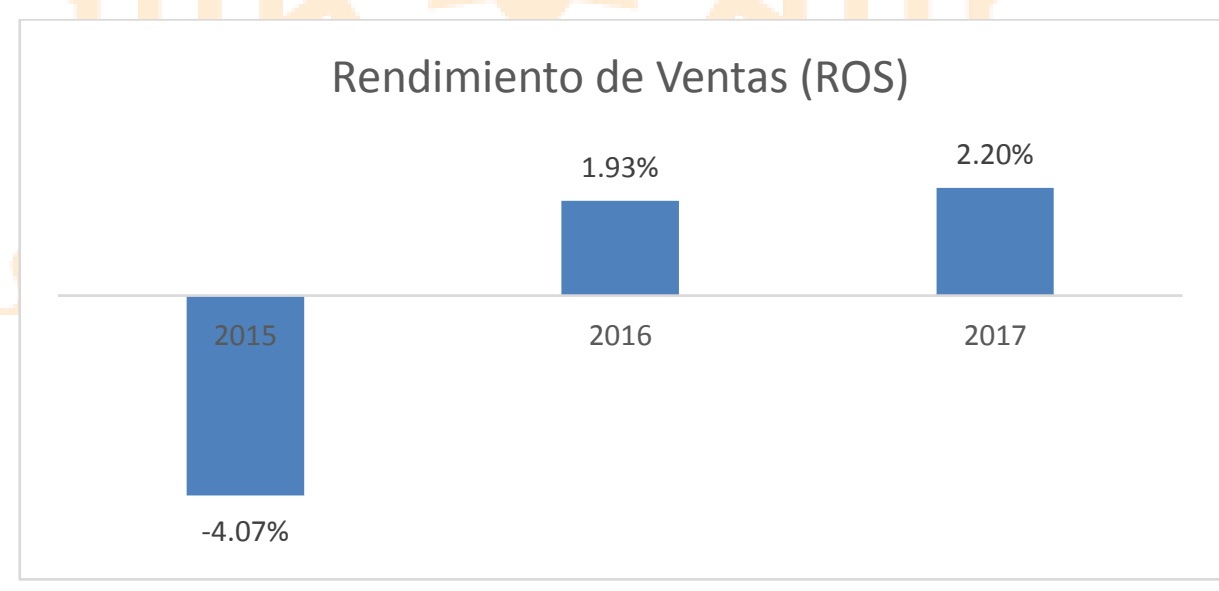

Fuente: Elaboración Propia

Podemos notar que en el año 2015 el indicador de Rendimiento sobre ventas se ve seriamente afectado por el resultado (Utilidad Neta negativa) como consecuencia de la pérdida neta obtenida en el mismo año (Venta del 100\% de su participación en la empresa XION I PARTICIPAÇÕES S.A., empresa brasilera). 
Durante los años 2016 el resultado sobre las ventas se ve positivamente afectado, considerando el volumen de ventas de productos, incluyendo agentes de voladura, ha tenido un incremento del $14.4 \%$ sustentado principalmente por el aumento de ventas de Dinamitas en el mercado regional y la adjudicación de dos contratos importantes de Tajo Abierto como son Chinalco y Antapaccay, es decir retomar su liderazgo en el mercado de minería de tajo abierto en el año 2016 respecto al 2015, adicional a ello priorizaron la optimización los costos de producción , logrado reducir precios de las materias primas, enfocándonos en el $20 \%$ de materiales que representaban el $80 \%$ de los costos, generando beneficios económicos sostenibles. A su vez se trabajó la búsqueda de proveedores alternativos, tanto a nivel local como internacional, para mejorar la continuidad del abastecimiento.

Con respecto al rendimiento obtenido en el año 2017, tuvo un incremento, muy a pesar de que sus ventas bajaron en un $3.79 \%$, básicamente originado por que se tuvieron como objetivo la optimización de los costos logísticos de aquellas materias primas consideradas estratégicas por representar el $90 \%$ de los costos, con el fin de generar beneficios sostenibles. Del mismo modo, se enfocan en la consolidación de acuerdos de abastecimiento de largo plazo y en la búsqueda de proveedores alternativos con el fin de garantizar el abastecimiento continuo y confiable.

\section{EBITDA}

Figura 4. 13 EBITDA

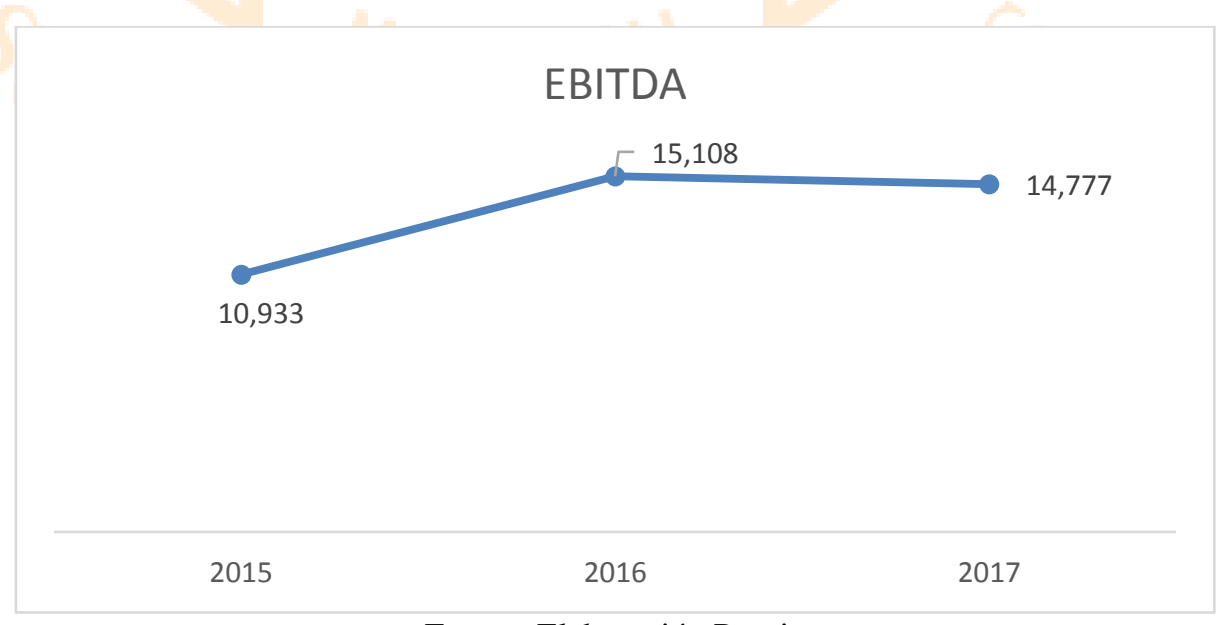

Fuente: Elaboración Propia 
En el ejercicio 2017, la empresa obtuvo Ventas menores en un $3.79 \%$ en comparación con las del 2016, es por ello que tuvieron como resultado un EBITDA menor en $2.19 \%$ con respecto al 2016, sin embargo, la variación no es tan drástica como sucedió en el 2016 y 2015, en el cual EXSA tuvo un incremento del 14.4\% en sus ventas, principalmente de dinamita en el mercado regional y la adjudicación de dos contratos importantes de Tajo Abierto con clientes como Chinalco y Antapacay.

En el caso de los gastos operativos de los 3 años no ha tenido mayor variación significativa.

\subsection{Presentación y Discusión de Resultados}

El presente trabajo se ha enfocado en analizar los estados financieros de la compañía de explosivos EXSA S.A.

La empresa mantiene su capacidad para cumplir sus obligaciones inmediatas. Comparando el resultado de la ratio corriente, podemos detectar que para el año 2017 se incrementó en 0.05 con respecto al resultado del 2016, dicho incremento se generó por la disminución de las cuentas por pagar comerciales y las de otros pasivos financieros (pago de préstamos bancarios). Así mismo tanto el efectivo y las cuentas por cobrar del año 2017 con las del 2016 disminuyeron, básicamente por la utilización de los fondos en las actividades de financiamiento e inversión.

En el año 2015 y 2016 la compañía mantuvo la capacidad de afrontar sus obligaciones con activos corrientes, sin considerar los inventarios (elemento menos liquido de los activos circulantes) para el 2017 no cubre el 100\% de sus obligaciones a corto plazo, solo el $86 \%$ sin vender los productos, sin embargo, debemos de tener en cuenta que los volúmenes totales de ventas de productos, incluyendo agentes de voladura, han tenido un incremento del $2.2 \%$ versus el 2016.

Con respecto al capital de trabajo el resultado es positivo y constante durante los años revisados, sin embargo, ha ido disminuyendo, porque la empresa utilizo fondos disponibles en actividades de financiamiento y de inversión (Préstamos otorgados a EXSA Chile para Capital de trabajo, el desarrollo de la planta iniciación de explosivos Proyecto NAZCA y aportes realizados a EXSA Colombia e International Blasting Service). 
EXSA cuenta con suficiente independencia financiera, considerando que por cada USD 61 de financiación ajena (Pasivo) la empresa cuenta con USD 100 financiamiento propio. Actualmente la empresa tiene préstamos bancarios por un total USD 51,773 (000) correspondiente a inversiones a el proyecto de la nueva planta de sistemas de iniciación, así como adquisición de camiones-fábrica, entre otros.

Podemos decir que la empresa al año 2017 muestra mayor eficiencia con respecto al año anterior, en relación a los días promedio de cobranzas, sin embargo, aún son mayores que los días promedio de pago, lo cual significaría posibles problemas en la tesorería, considerando que están pagando, en promedio, las obligaciones con proveedores antes de que ingrese flujo dinero por la cobranza.

Con respecto a los indicadores de rentabilidad se puede apreciar que en el año 2017 en comparación a años anteriores (2016 y 2015) la empresa ha generado beneficios económicos del $3.27 \%$ con respecto al exclusivo aporte de los dueños (ROE), así como un incremento con relación al 2016, del total de recursos que la empresa posee el cual contribuye en $2.03 \%$ en la generación de beneficio económico (ROA).

EXSA tuvo un incremento en el rendimiento en ventas, muy a pesar de que sus ventas bajaron en un $3.79 \%$, básicamente originado por que se tuvieron como objetivo la optimización de los costos logísticos de aquellas materias primas consideradas estratégicas por representar el $90 \%$ de los costos, con el fin de generar beneficios sostenibles.

La empresa obtuvo Ventas menores en un $3.79 \%$ en comparación con las del 2016, es por ello que tuvieron como resultado un EBITDA menor en $2.19 \%$ respecto al año anterior, sin embargo, la variación no es tan drástica como sucedió en el año 2015, básicamente por una disminución en el resultado de venta (21.51\%) y el costo de venta represento el $74 \%$ las ventas netas, lo cual se debe principalmente a la mayor composición las ventas de productos destinados al mercado de Tajo abierto, con clientes como Chinalco y Antapacay. 


\section{Resumen de ratios}

\begin{tabular}{|c|c|c|c|c|}
\hline \multirow[b]{2}{*}{ Tipo } & \multirow[b]{2}{*}{ Razón } & \multicolumn{3}{|c|}{ AÑOS } \\
\hline & & 2015 & 2016 & 2017 \\
\hline \multirow[t]{3}{*}{ Liquidez } & Razón Corriente & 2.34 & 1.80 & 1.85 \\
\hline & Ratio Prueba ácida & 1.37 & 1.11 & 0.86 \\
\hline & Capital de trabajo o fondo de maniobra & 59,098 & 47,622 & 34,351 \\
\hline \multirow[t]{2}{*}{ Endeudamiento } & Ratio de Endeudamiento & 0.50 & 0.74 & 0.61 \\
\hline & Grado de Propiedad & $67 \%$ & $57 \%$ & $62 \%$ \\
\hline \multirow[t]{5}{*}{ Actividad } & Periodo Promedio de cobro & 72 & 83 & 65 \\
\hline & Periodo Promedio de Inventarios & 121 & 117 & 120 \\
\hline & Periodo Prom Cuentas por Pagar & 34 & 71 & 44 \\
\hline & Ciclo Operativo & 193 & 200 & 184 \\
\hline & Ciclo de Conversion Efectivo & 158 & 130 & 140 \\
\hline \multirow[t]{5}{*}{ Crecimiento y Rentabilidad } & Crecimiento Ventas & $-21.51 \%$ & $4.32 \%$ & $-3.79 \%$ \\
\hline & Rendimiento de Ventas (ROS) & $-4.07 \%$ & $1.93 \%$ & $2.20 \%$ \\
\hline & Gastos Financ. a ventas & $0.59 \%$ & $0.25 \%$ & $0.31 \%$ \\
\hline & Utilidad a Activos (ROA) & $-4.29 \%$ & $1.77 \%$ & $2.03 \%$ \\
\hline & Utilidad a Patrimonio (ROE) & $-6.44 \%$ & $3.08 \%$ & $3.27 \%$ \\
\hline \multirow[t]{4}{*}{ Indicadores de Rentabilidad } & EBITDA & 10,736 & 14,872 & 14,777 \\
\hline & EBITDA/Gastos Financieros & 10.67 & 33.20 & 28.15 \\
\hline & EBIT/EBITDA & 0.56 & 0.66 & 0.59 \\
\hline & EBITDA/VENTAS /(Margen EBITDA) & $6.28 \%$ & $8.34 \%$ & $8.62 \%$ \\
\hline
\end{tabular}

Fuente: Elaboración Propia

\subsection{Proyecciones}

A continuación, se presentan los estados financieros proyectados, los cuales se elaboraron en función a una formula financiera de tendencias, en razón de las ventas históricas.

La fórmula de línea de tendencia es la Polinómica, debemos tener en consideración que dicha fórmula pronostica en función a información histórica de la venta de la empresa EXSA S.A. durante los años 2013 al 2017, con el fin de pronosticar la Demanda para los años 2018 al 2020. 
Ingresos de Actividades Ordinarias US\$

(000)

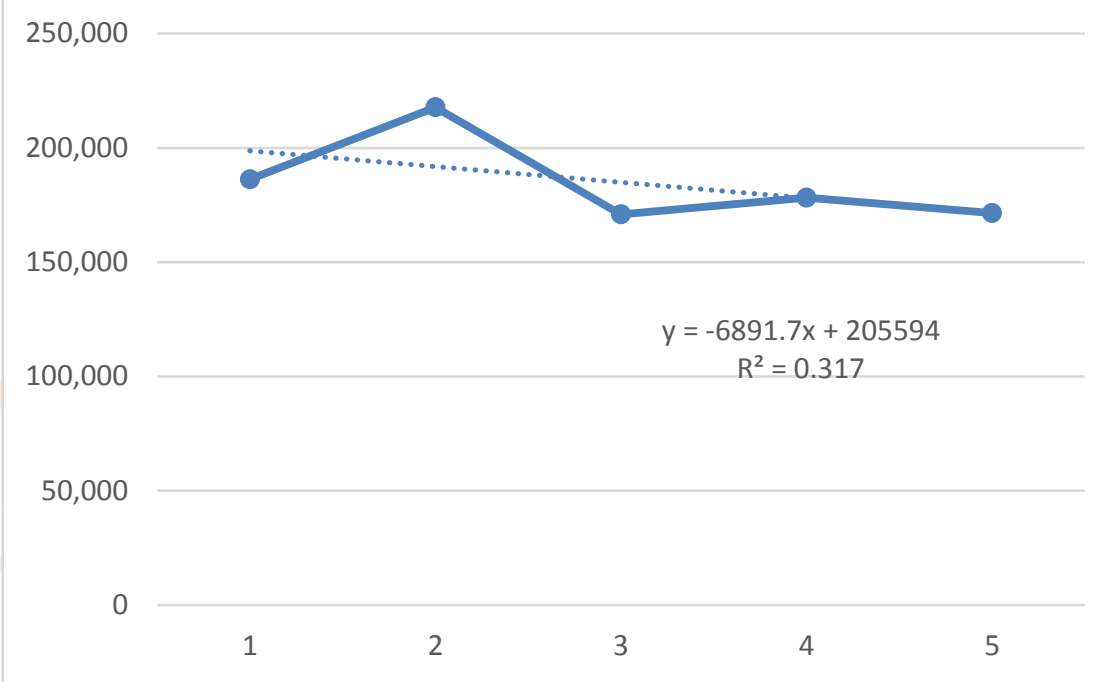

Fuente: Elaboración Propia

\section{Estado de resultados proyectado}

Podemos notar que la demanda proyectada, con la formula predictiva, disminuye en el año 2018 


\begin{tabular}{|c|c|c|c|c|c|c|c|}
\hline & \multicolumn{3}{|c|}{ Años Analizados } & \multirow{2}{*}{$\begin{array}{l}\text { \%(BASE } \\
\text { VENTAS) }\end{array}$} & \multicolumn{3}{|c|}{ Años Provectados } \\
\hline & 2015 & 2016 & 2017 & & 2018 & 2019 & 2020 \\
\hline \multicolumn{8}{|c|}{ \% Projección (Segginformula de tendencias } \\
\hline Aplicada a Ventas historicas) & & & & & $-4,23 \%$ & $-4.20 \%$ & $-438 \%$ \\
\hline Ingresesos de Actwivaddes Ordinarias & 170,886 & 178,260 & 171,502 & $100 \%$ & 164,244 & 157,352 & 150,460 \\
\hline Costo de Ventasl & $-126,451$ & 126,005 & 120,540 & $.71 .66 \%$ & - 117,691 & $-112,752$ & 107,814 \\
\hline Ganancia (Pérdida) Brita & 44,435 & 52,255 & 50,962 & $28.34 \%$ & 46,553 & 44,000 & 42,646 \\
\hline Gastos de Ventas y Distribución & $-23,986$ & $-26,528$ & $-24,978$ & $.14 .49 \%$ & $-23,806$ & $-22,807$ & $-21,008$ \\
\hline Gastos de Administración & $-14,992$ & $-16,319$ & -17,946 & $-9.46 \%$ & $.15,544$ & $-14,992$ & $-14,239$ \\
\hline Otros Ingresesos Operativios & 1,684 & 3,012 & 3,507 & $1.57 \%$ & 2,584 & 2,476 & 2,367 \\
\hline Otros Gastos Operativos & $-1,078$ & $-2,591$ & $-2,798$ & $-1.24 \%$ & $-2,034$ & $-1,449$ & $-1,864$ \\
\hline Ganancia (Pérdida) Operatival & 6,063 & 9,829 & 8,747 & $4.72 \%$ & 7,753 & 7,428 & 7,103 \\
\hline Ingressos Fimancierosl & 53 & 142 & 533 & $0.14 \%$ & 231 & 221 & 211 \\
\hline Gastos Financieros/ & $-1,006$ & -448 & .525 & $0.38 \%$ & 627 & 601 & 575 \\
\hline
\end{tabular}

Otros hogressos (Gastos) Subsidarias, Ascoialas y

$\begin{array}{llllllll}\text { Neggocios Conjuntos } & -6,245 & -2,479 & -1,983 & -2,07 \% & -3,395 & -3,253 & -3,110\end{array}$

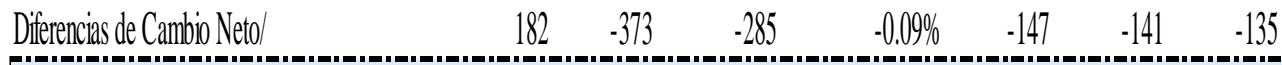

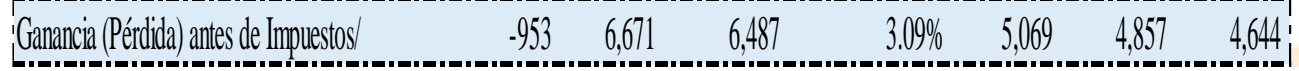

$\begin{array}{llllllll}\text { Ingreso (Gasto) por Impuestol } & -6,005 & -3,239 & -2,721 & -0.07 \% & -117 & -112 & -107\end{array}$

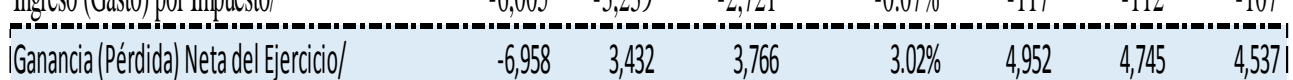

Fuente: Elaboración Propia 


\section{Estados de situación financiera proyectado}

\begin{tabular}{|c|c|c|c|c|c|c|c|}
\hline & \multicolumn{3}{|c|}{ Años Analizados } & \multirow{2}{*}{$\begin{array}{l}\% \text { (BASE } \\
\text { VENTAS) }\end{array}$} & \multicolumn{3}{|c|}{ Años Proyectados } \\
\hline & 2015 & 2016 & 2017 & & 2018 & 2019 & 2020 \\
\hline \multicolumn{8}{|l|}{$\begin{array}{l}\text { \% Proyección (Según formula de } \\
\text { tendencias Aplicada a Total Activos y }\end{array}$} \\
\hline Total Patrimonio Anuales historicas) & & & & & $-1.85 \%$ & $-0.52 \%$ & $-0.52 \%$ \\
\hline Efectivo y Equivalentes al Efectivo & 7949 & 5980 & 571 & $8.82 \%$ & 16,051 & 15,968 & 15,884 \\
\hline Cuentas por Cobrar Comerciales & 35277 & 33214 & 28940 & $18.45 \%$ & 33,590 & 33,416 & 33,243 \\
\hline Cuentas por Cobrar a Entidades Relacio & 327 & 2544 & 1835 & $1.14 \%$ & 2,069 & 2,058 & 2,047 \\
\hline Otras Cuentas por Cobrar & 3760 & 3015 & 2206 & $1.04 \%$ & 1,901 & 1,891 & 1,881 \\
\hline Inventarios & 47056 & 51592 & 40018 & $22.96 \%$ & 41,800 & 41,583 & 41,367 \\
\hline Gastos Pagados por Anticipado & 87 & 407 & 1216 & $0.64 \%$ & 1,172 & 1,166 & 1,160 \\
\hline Total Activos Corrientes & 94456 & 96752 & 74786. & $53.06 \%$ & 96,582 & 96,082 & 95,583 \\
\hline Activos No Corrientes & & & & & & - & - \\
\hline \multicolumn{8}{|l|}{ Inversiones en Subsidiarias, Negocios } \\
\hline Conjuntos y Asociadas & 49111 & 44692 & 272 & $0.24 \%$ & 437 & 435 & 433 \\
\hline Cuentas por Cobrar a Entidades Relacio & 0 & 0 & 13483 & $2.78 \%$ & 5,067 & 5,040 & 5,014 \\
\hline Propiedades, Planta y Equipo & 44691 & 45172 & 94872 & $42.69 \%$ & 77,711 & 77,309 & 76,907 \\
\hline Activos Intangibles Distintos de la Plusva & 1500 & 1964 & 1246 & $0.78 \%$ & 1,422 & 1,415 & 1,407 \\
\hline Activos por Impuestos Diferidos & 2956 & 607 & 0 & $0.00 \%$ & - & - & - \\
\hline Plusvalía & 0 & 0 & 774 & $0.43 \%$ & 784 & 780 & 776 \\
\hline Otros Activos no Financieros & 53 & 30 & 17. & $0.01 \%$ & 18 & 18 & 18 \\
\hline Total Activos No Corrientes & 98311 & 92465 & 110664 & $46.94 \%$ & 85,439 & 84,997 & 84,555 \\
\hline TOTAL ACTIVOS & 192767 & 189217 & 185450 & $100 \%$ & 182,021 & 181,079 & 180,138 \\
\hline \multicolumn{8}{|l|}{ Pasivos y Patrimonio } \\
\hline \multicolumn{8}{|l|}{ Pasivos Corrientes } \\
\hline Otros Pasivos Financieros & 23771 & 31646 & 13570 & $11.65 \%$ & 21,211 & 21,101 & 20,991 \\
\hline Cuentas por Pagar Comerciales & 19750 & 19607 & 14011 & $8.93 \%$ & 16,264 & 16,179 & 16,095 \\
\hline \multicolumn{8}{|l|}{ Cuentas por Pagar a Entidades } \\
\hline Relacionadas & 621 & 490 & 849 & $0.45 \%$ & 823 & 818 & 814 \\
\hline Otras Cuentas por Pagar & 8347 & 7494 & 10997 & $5.14 \%$ & 9,358 & 9,309 & 9,261 \\
\hline Ingresos Diferidos & 838 & 1513 & 1008 & $0.41 \%$ & 742 & 738. & 735 \\
\hline Total Pasivos Corrientes & 53327. & 60750 & 40435. & $26.59 \%$ & 48,397 & 48,147 & 47,896 \\
\hline \multicolumn{8}{|l|}{ Pasivos No Corrientes } \\
\hline Otros Pasivos Financieros & 33564 & 27918 & 29338 & $10.97 \%$ & 19,965 & 19,862 & 19,758 \\
\hline \multicolumn{8}{|l|}{ Cuentas por Pagar Comerciales y Otras } \\
\hline Cuentas por Pagar & 0 & 0 & 0 & $0.00 \%$ & 2 & 2 & 2 \\
\hline Pasivos por Impuestos Diferidos & & 0 & 441. & $0.44 \%$ & 805 & 801. & 797 \\
\hline Total Pasivos No Corrientes & 33564 & 27918 & 29779 & $11 \%$ & 20,771 & 20,664 & 20,556 \\
\hline Total Pasivos & 86891 & 88668 & 70214 & $38 \%$ & 69,168 & 68,811 & 68,453 \\
\hline \multicolumn{8}{|l|}{ Patrimonio } \\
\hline Capital Emitido & 37066 & 37066 & 37066 & $20.63 \%$ & 37,545 & 37,351 & 37,157 \\
\hline Acciones de Inversión & 18533 & 18533 & 18533 & $10.31 \%$ & 18,773 & 18,676 & 18,578 \\
\hline Otras Reservas de Capital & 6263 & 8086 & 8997 & $5.01 \%$ & 9,113 & 9,066 & 9,019 \\
\hline Resultados Acumulados & 42932 & 44723 & 44052 & $22.39 \%$ & 40,757 & 40,546 & 40,335 \\
\hline Otras Reservas de Patrimonio & 1082 & -7859 & 6588. & $3.66 \%$ & 6,664 & $6,630$. & 6,595 \\
\hline Total Patrimonio & 105876 & 100549 & 115236. & $62 \%$ & 112,852 & 112,269 & 111,685 \\
\hline TOTAL PASIVOS Y PATRIMONIO & 192767 & 189217 & 185450 & $100 \%$ & 182,021 & 181,079 & 180,138 \\
\hline
\end{tabular}

Fuente: Elaboración Propia 


\subsection{Proyección Alternativa}

A continuación, se presentan los estados financieros proyectados, los cuales se elaboraron en función al promedio de 4 factores que pueden influenciar en las ventas de EXSA, considerando la oportunidad de reforzar su participación en el sector de construcción.

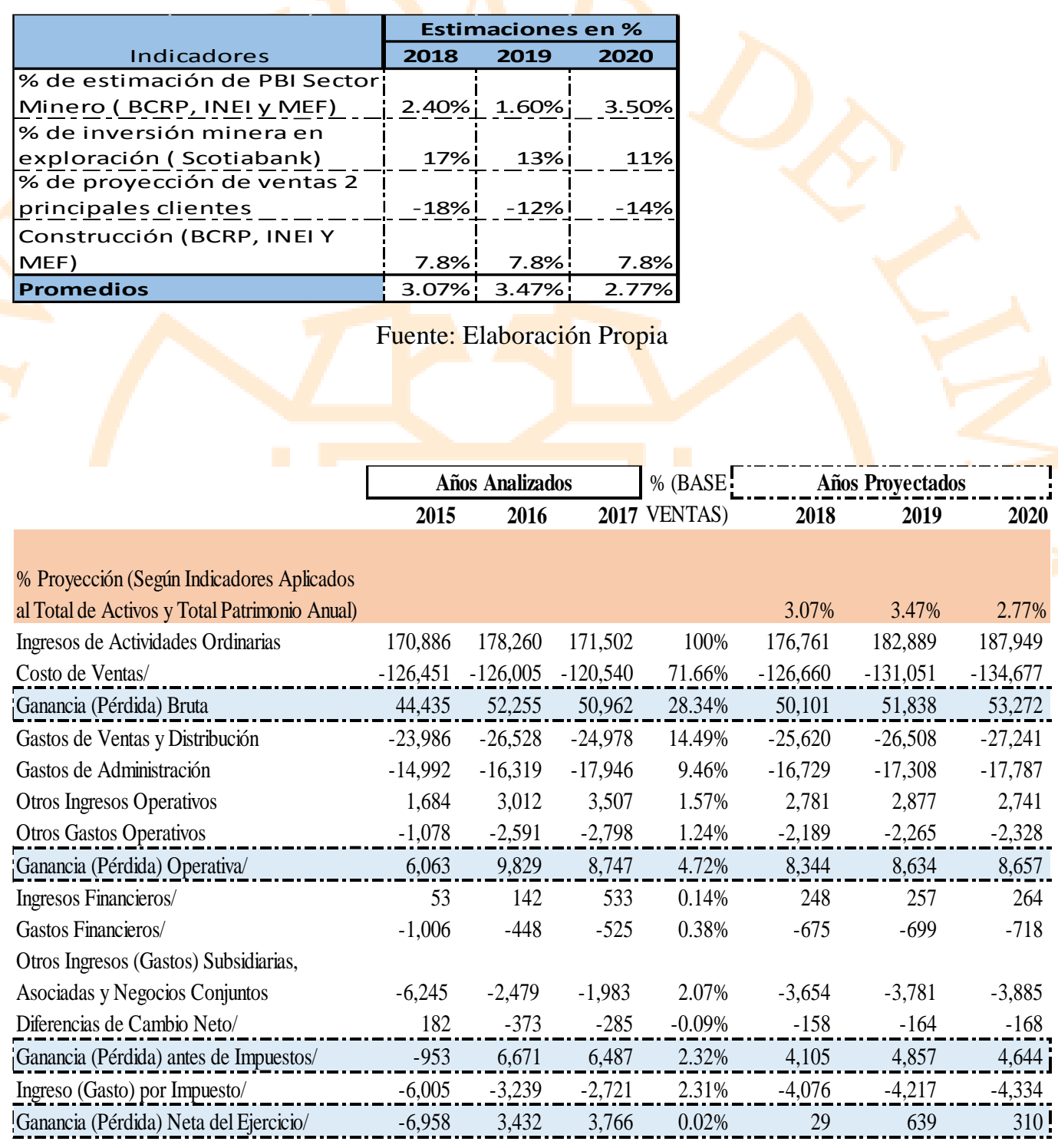




\begin{tabular}{|c|c|c|c|c|c|c|c|}
\hline & \multicolumn{3}{|c|}{ Años Analizados } & \multicolumn{3}{|c|}{$\%$ (BASE! Años Proyectados } & \multirow{2}{*}{2020} \\
\hline & 2015 & 2016 & 2017 & VENTAS) & 2018 & 2019 & \\
\hline \multicolumn{8}{|l|}{ \% Proyección (Según Indicadores Aplicados } \\
\hline al Total de Activos y Total Patrimonio Anual) & & & & & $3.07 \%$ & $3.47 \%$ & $2.77 \%$ \\
\hline Efectivo y Equivalentes al Efectivo & 7,949 & 5,980 & 571 & $8.82 \%$ & 16,854 & 17,439 & 17,921 \\
\hline Cuentas por Cobrar Comerciales & 35,277 & 33,214 & 28,940 & $18.45 \%$ & 35,272 & 36,495 & 37,505 \\
\hline Cuentas por Cobrar a Entidades Relacionadas & 327 & 2,544 & 1,835 & $1.14 \%$ & 2,172 & 2,248 & 2,310 \\
\hline Otras Cuentas por Cobrar & 3,760 & 3,015 & 2,206 & $1.04 \%$ & 1,996 & 2,065 & 2,123 \\
\hline Inventarios & 47,056 & 51,592 & 40,018 & $22.96 \%$ & 43,893 & 45,415 & 46,671 \\
\hline Gastos Pagados por Anticipado & 87. & 407 & 1,216 & $0.64 \%$ & $1,231$. & 1,273 & 1,309 \\
\hline Total Activos Corrientes & 94,456 & 96,752 & 74,786 & $53.06 \%$ & 101,419 & 104,935 & 107,838 \\
\hline Activos No Corrientes & & & & & & - & - \\
\hline Inversiones en Subsidiarias & 49,111 & 44,692 & 272 & $0.24 \%$ & 459 & 475 & 488 \\
\hline Cuentas por Cobrar a Entidades Relacionadas & - & - & 13,483 & $2.78 \%$ & 5,320 & 5,505 & 5,657 \\
\hline Propiedades, Planta y Equipo & 44,691 & 45,172 & 94,872 & $42.69 \%$ & 81,603 & 84,432 & 86,768 \\
\hline Activos Intangibles Distintos de la Plusvalía & 1,500 & 1,964 & 1,246 & $0.78 \%$ & 1,493 & 1,545 & 1,588 \\
\hline Activos por Impuestos Diferidos & 2,956 & 607 & - & $0.00 \%$ & - & - & - \\
\hline Plusvalía & - & - & 774 & $0.43 \%$ & 823 & 852 & 875 \\
\hline Otros Activos no Financieros & 53. & 30. & 17. & $0.01 \%$ & 19. & 19 & 20 \\
\hline Total Activos No Corrientes & 98,311 & 92,465 & 110,664 & $46.94 \%$ & 89,718 & 92,828 & 95,397 \\
\hline TOTAL ACTIVOS & 192,767 & 189,217 & 185,450 & $100 \%$ & 191,137 & 197,763 & 203,235 \\
\hline \multicolumn{8}{|l|}{$\begin{array}{l}\text { Pasivos y Patrimonio } \\
\text { Pasivos Corrientes }\end{array}$} \\
\hline Otros Pasivos Financieros & 23,771 & 31,646 & 13,570 & $11.65 \%$ & 22,273 & 23,045 & 23,683 \\
\hline Cuentas por Pagar Comerciales & 19,750 & 19,607 & 14,011 & $8.93 \%$ & 17,078 & 17,670 & 18,159 \\
\hline Cuentas por Pagar a Entidades Relacionadas & 621 & 490 & 849 & $0.45 \%$ & 864 & 894 & 918 \\
\hline Otras Cuentas por Pagar & 8,347 & 7,494 & 10,997 & $5.14 \%$ & 9,827 & 10,167 & 10,448 \\
\hline Ingresos Diferidos & 838. & $1,513$. & 1,008 & $0.41 \%$ & 779. & 806 & 829 \\
\hline Total Pasivos Corrientes & 53,327 & 60,750 & 40,435 & $26.59 \%$ & 50,821 & 52,583 & 54,038 \\
\hline \multicolumn{8}{|l|}{ Pasivos No Corrientes } \\
\hline Otros Pasivos Financieros & 33,564 & 27,918 & 29,338 & $10.97 \%$ & 20,965 & 21,692 & 22,292 \\
\hline \multicolumn{8}{|l|}{ Cuentas por Pagar Comerciales y Otras } \\
\hline Cuentas por Pagar & - & - & - & $0.00 \%$ & 2 & 2 & 2 \\
\hline Pasivos por Impuestos Diferidos & & - & 441. & $0.44 \%$ & 845. & 874 & 899 \\
\hline Total Pasivos No Corrientes & 33,564 & 27,918 & 29,779 & $11 \%$ & 21,812 & 22,568 & 23,192 \\
\hline Total Pasivos & 86,891 & 88,668 & 70,214 & $38 \%$ & 72,633 & 75,151 & 77,230 \\
\hline \multicolumn{8}{|l|}{ Patrimonio } \\
\hline Capital Emitido & 37,066 & 37,066 & 37,066 & $20.63 \%$ & 39,426 & 40,793 & 41,921 \\
\hline Acciones de Inversión & 18,533 & 18,533 & 18,533 & $10.31 \%$ & 19,713 & 20,396 & 20,961 \\
\hline Otras Reservas de Capital & 6,263 & 8,086 & 8,997 & $5.01 \%$ & 9,570 & 9,902 & 10,175 \\
\hline Resultados Acumulados & 42,932 & 44,723 & 44,052 & $22.39 \%$ & 42,798 & 44,281 & 45,507 \\
\hline Otras Reservas de Patrimonio & $1,082$. & $-7,859$. & $6,588$. & $3.66 \%$ & 6,998. & 7,241 & . 7,441 \\
\hline Total Patrimonio & 105,876 & 100,549 & 115,236 & $62 \%$ & 118,505 & 122,613 & 126,005 \\
\hline TOTAL PASIVOS Y PATRIMONIO & 192,767 & 189,217 & 185,450 & $100 \%$ & 191,137 & 197,763 & 203,235 \\
\hline
\end{tabular}

\subsection{Impacto de las NIIF 9, 15 y 16 en los Estados Financieros Proyectados}

\section{NIIF 9: Instrumentos Financieros}

La norma plantea cambios en la clasificación y medición de instrumentos financieros, el deterioro de los activos financieros, la contabilidad de cobertura y la contabilización de modificaciones de pasivos financieros.

La NIIF 9 incluye 3 categorías de clasificación principales para los activos financieros:

- Medidos al costo amortizado.

- Al valor razonable con cambios en otro resultado integral.

- Al valor razonable con cambios en el estado de resultados. 
La norma elimina las categorías existentes de la NIC 39 de mantenidos hasta el vencimiento, préstamos y partidas por cobrar y disponibles para la venta.

\section{NIIF 15: Ingresos procedentes de contratos con clientes}

La norma en cuestión establece un modelo de 5 pasos que será aplicado en ingresos de actividades ordinarias procedentes de contratos con clientes. Según la NIIF, el ingreso es reconocido por el importe que refleja la contraprestación contractual que ha sido acordada con el cliente. Los principios que plantea la norma proporcionan un enfoque prescriptivo y más estructurado para medir y reconocer los ingresos.

La compañía deberá reconocer las dos obligaciones de desempeño incluidas como parte de las ventas locales de producto: Venta de productos y el servicio de asistencia técnica como obligación de desempeño implícita.

A sí mismo la NIIF 15 requiere la separación del ingreso entre estos dos elementos, en función al precio de venta independientemente relacionado.

\section{NIIF 16: Arrendamiento}

La norma establece los principios para el reconocimiento, medición, presentación e información a revelar para los arrendamientos y requiere que se contabilicen todos los arrendamientos bajo un único modelo, similar a la contabilización de los arrendamientos financieros (NIC 17). La norma incluye dos excepciones al reconocimiento para los arrendatarios, las cuales son: arrendamientos a corto plazo y aquellos en los que el activo subyacente es de bajo valor.

Según la norma a la fecha de inicio de un contrato, el arrendatario reconocerá un pasivo por el valor presente de los pagos por el arrendamiento que no se hayan pagado en esa fecha y un Activo por derecho de uso del activo durante el plazo del arrendamiento.

Los arrendatarios deberán reconocer por separado el gasto por intereses sobre el pasivo por el arrendamiento y el gasto de depreciación por el derecho de uso del activo.

Por último, los arrendatarios también estarán obligados a volver a valorizar el pasivo del arrendamiento al ocurrir ciertos eventos, como cambios en el plazo del arrendamiento o cambios en los pagos futuros del arrendamiento que resulten de un 
cambio en el índice o la tasa utilizada para la determinación de dichos pagos. El arrendatario reconocerá el monto de dicha valorización del pasivo como un ajuste en el correspondiente derecho de uso del activo.

El primer impacto de la aplicación de la NIIF 16 por la adopción para EXSA es el reconocimiento en el estado de situación financiera de contratos en los que tiene derecho de uso de activos, asociados principalmente con arrendamientos operativos y ciertos de contratos de servicios que contienen arrendamientos implícitos. El impacto más representativo corresponde al alquiler a una entidad relacionada de terrenos en los que opera la planta productiva de la empresa, el plazo ha sido estimado en función de la expectativa de uso de la empresa. 


\section{CAPITULO V: CONCLUSIONES Y RECOMENDACIONES}

\subsection{Conclusiones}

Con respecto a la Liquidez de la empresa EXSA, podemos decir que según los resultados obtenidos en general no tiene la capacidad de satisfacer sus obligaciones a corto plazo, más aun si deducimos los inventarios de sus recursos a corto plazo, conforme han pasado los años, dicha capacidad va disminuyendo por efecto de la drástica diminución del efectivo o equivalente de efectivo en el año 2017, la cual tuvo como origen la utilización del efectivo para actividades de financiamiento e inversión.

El resultado obtenido de los índices de Actividad o gestión podemos detectar que el periodo promedio de pago es menor al periodo promedio de cobro, el ideal es que suceda al revés, es decir primero los clientes pagan a EXSA y luego la empresa les paga a los proveedores. En el caso del ciclo de efectivo resultante en los 3 años analizados no es estable, sin embargo, para el 2017 aumenta en 10 días en comparación con el año anterior, lo cual indica que la empresa está vendiendo sus productos o servicios más lentamente, los días de cobranza son mayores o hace falta una mejor negociación con la condición de pago a proveedores.

En el caso de la capacidad de endeudamiento de la compañía, El endeudamiento con terceros constituido en el pasivo total representa solo el $61 \%$ del patrimonio neto de la empresa en el año2017. Si bien esto otorga solvencia, pero representa riesgo para los accionistas al ser ellos los que financian en mayor porcentaje a la empresa, sin embargo, comparando el endeudamiento del 2017 con respecto al año 2016 ha disminuido en 0.13 . lo cual fue originado por la disminución de los pasivos totales, principalmente los pasivos a corto plazo. Así mismo evaluando la ratio de grado de propiedad se ve incrementado para el 2017 en 5\% lo cual indica una mayor fuerza financiera a largo plazo porque se hace un menor uso de deudas que tienen fechas definidas de vencimiento y pagos periódicos obligatorios.

En el caso de los resultados obtenidos de los indicadores de crecimiento y rentabilidad ha mejorado durante los dos últimos años, pero no lo suficiente, considerando que el rendimiento sobre los Activos debería de superar el 5\%, es decir, 
la empresa no está siendo lo suficientemente eficiente con el uso de sus activos. Con respecto al rendimiento sobre la inversión se ha incrementado satisfactoriamente, durante los años evaluados, sin embargo, la empresa requiere mejorar su capacidad para generar rentabilidad a través de un equilibrio entre la obtención de utilidades respecto al nivel de ventas generada.

Podemos apreciar que el primer factor de desarrollo que se ha planteado EXSA ha sido el enfoque regional, donde han utilizado como modos de entrada las exportaciones y la inversión extranjera directa (inversión en subsidiarias).

Debemos de tener en consideración el respaldo de un grupo financiero, como es el Grupo Breca que es quien soporta el crecimiento de la empresa es muy importante puesto que abre muchas puertas desde financiamiento hasta proveedores y clientes que tienen de una u otra forma alguna relación con alguna de las empresas del grupo.

\subsection{Recomendaciones}

Para poder mejorar sus indicadores financieros EXSA deberá de considerar el tener planes de acción:

- Mejorar la capacidad de generar efectivo o equivalente de efectivo mediante los cobros, es decir mejorar el periodo promedio de cobranzas, a través de uso de herramientas capaces de generar mayor liquidez (letras descontadas o factoring, cartas de crédito, etc.) así como renegociar con los proveedores actuales o buscar proveedores alternativos con el objetivo de obtener mejores condiciones de pago y garantizar el abastecimiento continuo, a fin de que el promedio ponderado de pago sea menor al de cobro, sin afectar la calidad del abastecimiento que nos brindas nuestros proveedores.

- Con el fin de mejorar sus resultados es necesario incrementar las ventas tanto nacionales, mayor participación en proyectos de minería y desarrollar estrategias que puedan generar mayor presencia en el sector de construcción, así como en las exportaciones.

- Incrementar la rotación de sus activos, es decir buscar, no solo incrementar el volumen de las ventas frente al saldo del activo, sino también el mejorar el margen neto, bajando los costos de las compras o renegociar los 
términos de compra con sus proveedores o encontrar nuevos proveedores que te puedan ofrecer mejores condiciones, precios, una calidad comparable a la actual y mejorar el control de gastos operativos, es decir buscar optimizar los ingresos. 


\section{REFERENCIAS}

EXSA S.A. (2014). Nosotros EXSA. Recuperado de https://exsa.net/nosotros/

Banco Mundial (24 Setiembre 2018). Perú Panorama General. Recuperado de http://www.bancomundial.org/es/country/peru/overview

Diario Gestión (30 Octubre 2015). Hasta 70\% de empresas mineras migrarían a tecnología verde en uso de explosivos Recuperado de https://gestion.pe/economia/empresas/70-empresas-mineras-migrariantecnologia-verde-explosivos-103769

Diario El Comercio (01 Febrero 2016). EXSA lanza explosivos menos contaminantes y más resistentes. Recuperado de https://elcomercio.pe/economia/negocios/exsa-lanza-explosivoscontaminantes-resistentes-268661 


\section{BIBLIOGRAFIA}

PORTER, M.E. (Enero 2008). Las cinco fuerzas competitivas que le dan forma a la estrategia. Harvard Business Review (América Latina). Recuperado de https://utecno.files.wordpress.com/2014/05/las_5_fuerzas_competitivas_michael_porter-libre.pdf

ROSS WESTERFIED JAFFE (2012). Finanzas Corporativas. (9 $9^{\mathrm{a}}$ ed.) En McGraw Hill/INTERAMERICANA EDITORES, S.A. México McGraw-Hill.

PERU SECTOR MINERO - BBVA RESEARCH (2017). Recuperado de https://www.bbvaresearch.com/wp-content/.../11/Sector-Minero-en$\underline{\text { Peru_2017.pdf }}$

Banco Central de Reserva del Perú (BCRP). Nota de Estudios $N^{\circ}$ 51: Actividad Económica (Mayo 2018). Recuperado de http://www.bcrp.gob.pe/docs/Publicaciones/Notas-Estudios/.../nota-deestudios-51-2018.pdf

INSTITUTO PERUANO DE ECONÓMIA (IPE). El valor agregado de la minería en el Perú ( $1^{\mathrm{a}}$ ed.) Instituto de Estudios Energético Minero (Junio 2017).

C.P.C./Abogado Henry Aguilar Espinoza. Análisis Práctico de las NIIF: Tratamiento contable y tributario ( $1^{\mathrm{a}}$ ed.) Entrelineas S.R.L. (2017 - II). 


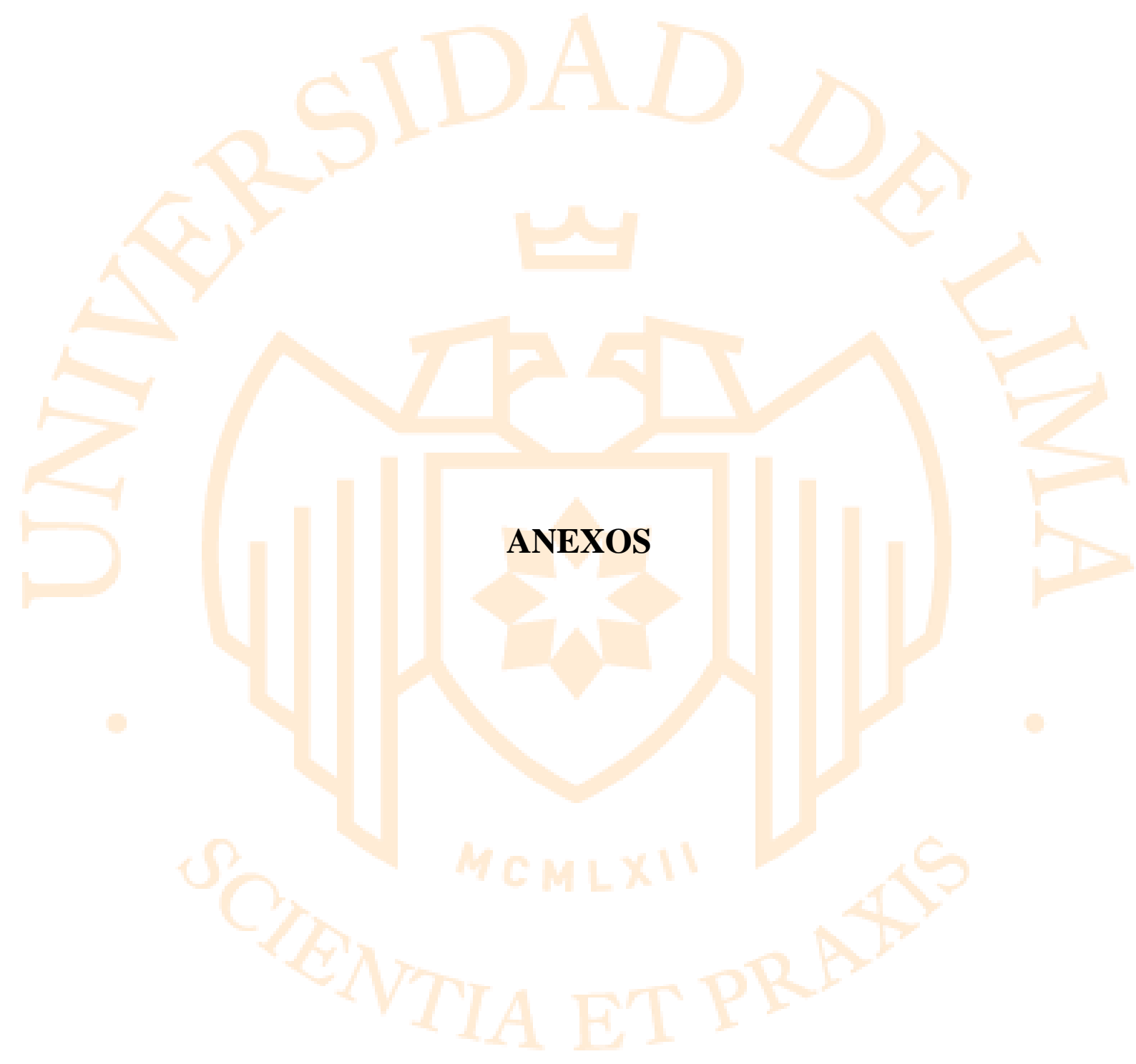




\section{Anexo 1 Estado de Situación Financiera}

\section{Estado de Situación Financiera (Separados y Auditados)}

Expresado en miles de USD Americanos (US\$ 000)

\begin{tabular}{|c|c|c|c|}
\hline & & Años & \\
\hline & 2015 & 2016 & 2017 \\
\hline Efectivo y Equivalentes al Efectivo & 24,645 & 21,322 & 571 \\
\hline Cuentas por Cobrar Comerciales & 31,471 & 39,611 & 28,940 \\
\hline Cuentas por Cobrar a Entidades Relacionadas & 2,572 & 1,625 & 1,835 \\
\hline Otras Cuentas por Cobrar & 1,235 & 2,300 & 2,206 \\
\hline Inventarios & 42,562 & 41,022 & 40,018 \\
\hline Gastos Pagados por Anticipado & 810 & 1,511 & 1,216 \\
\hline Total Activos Corrientes & 103,295 & 107,391 & 74,786 \\
\hline Activos No Corrientes & & & \\
\hline Inversiones en Subsidiarias, Negocios Conjuntos y Asociadas & 530 & 481 & 272 \\
\hline Cuentas por Cobrar a Entidades Relacionadas & - & 2,100 & 13,483 \\
\hline Propiedades, Planta y Equipo & 56,416 & 82,002 & 94,872 \\
\hline Activos Intangibles Distintos de la Plusvalía & 1,319 & 1,671 & 1,246 \\
\hline Activos por Impuestos Diferidos & - & - & - \\
\hline Plusvalía & 774 & 774 & 774 \\
\hline Otros Activos no Financieros & 18 & 18 & 17 \\
\hline Total Activos No Corrientes. & 59,057 & 87,046 & 110,664 \\
\hline TOTAL ACTIVOS & 162,352 & 194,437 & 185,450 \\
\hline Pasivos y Patrimonio & & & \\
\hline Pasivos Corrientes & & & \\
\hline Otros Pasivos Financieros & 23,000 & 26,200 & 13,570 \\
\hline Cuentas por Pagar Comerciales & 11,733 & 23,377 & 14,011 \\
\hline Cuentas por Pagar a Entidades Relacionadas & 364 & 1,310 & 849 \\
\hline Otras Cuentas por Pagar & 8,514 & 8,262 & 10,997 \\
\hline Ingresos Diferidos & 586 & 620. & 1,008 \\
\hline Total Pasivos Corrientes & 44,197 & 59,769 & 40,435 \\
\hline Pasivos No Corrientes & & & \\
\hline Otros Pasivos Financieros & 8,787 & 22,697 & 29,338 \\
\hline Cuentas por Pagar Comerciales y Otras Cuentas por Pagar & - & 5 & - \\
\hline Pasivos por Impuestos Diferidos & 1,351 & 499. & 441 \\
\hline Total Pasivos No Corrientes & 10,138 & 23,201 & 29,779 \\
\hline Total Pasivos & 54,335 & 82,970 & 70,214 \\
\hline Patrimonio & & & \\
\hline Capital Emitido & 37,066 & 37,066 & 37,066 \\
\hline Acciones de Inversión & 18,533 & 18,533 & 18,533 \\
\hline Otras Reservas de Capital & 8,997 & 8,997 & 8,997 \\
\hline Resultados Acumulados & 36,854 & 40,286 & 44,052 \\
\hline Otras Reservas de Patrimonio & 6,567 & $6,585$. & 6,588 \\
\hline Total Patrimonio & 108,017 & 111,467 & 115,236 \\
\hline TOTAL PASIVOS Y PATRIMONIO & 162,352 & 194,437 & 185,450 \\
\hline
\end{tabular}




\section{Anexo 2 Estado de Resultados}

Estado de Resultados (Separados y Auditados)

Expresado en miles de USD Americanos (US\$000)

\begin{tabular}{|c|c|c|c|}
\hline & & Años & \\
\hline & 2015 & 2016 & 2017 \\
\hline Ingresos de Actividades Ordinarias & 170,886 & 178,260 & 171,502 \\
\hline Costo de Ventas/ & $-126,451$ & $-126,005$ & $-120,540$ \\
\hline Ganancia (Pérdida) Bruta. & 44, 435 & $52,255$. & 50,962 \\
\hline Gastos de Ventas y Distribución & $-23,986$ & $-26,528$ & $-24,978$ \\
\hline Gastos de Administración & $-14,992$ & $-16,319$ & $-17,946$ \\
\hline Otros Ingresos Operativos & 1,684 & 3,012 & 3,507 \\
\hline Otros Gastos Operativos & $-1,078$ & $-2,591$ & $-2,798$ \\
\hline Ganancia (Pérdida) Operativa/ & 6,063 & 9,829 & 8,747 \\
\hline Ingresos Financieros/ & 53 & 142 & 533 \\
\hline Gastos Financieros/ & $-1,006$ & -448 & -525 \\
\hline Otros Ingresos (Gastos) Subsidiarias, Aso & & & \\
\hline Negocios Conjuntos & $-6,245$ & $-2,479$ & $-1,983$ \\
\hline Diferencias de Cambio Neto/ & 182 & -373. & -285 \\
\hline Ganancia (Pérdida) antes de Impuestos/ & -953 & 6,671 & 6,487 \\
\hline Ingreso (Gasto) por Impuesto/ & $-6,005$ & $-3,239$ & $-2,721$ \\
\hline Ganancia (Pérdida) Neta del Ejerciciol & $-6,958$ & 3,432 & 3,766i \\
\hline
\end{tabular}




\section{Anexo 3 Estado de Flujo de Efectivo}

Estado de Flujo de Efectivo (Separados y Auditados)

Expresado en miles de USD Americanos (US\$000)

\begin{tabular}{|c|c|c|c|}
\hline & \multicolumn{3}{|c|}{ Años } \\
\hline & 2015 & 2016 & 2017 \\
\hline \multicolumn{4}{|l|}{ Actividades de operación } \\
\hline Cobranzas a clientes y terceros & 172,729 & 170,655 & 182,796 \\
\hline Pagos a proveedores & $-136,113$ & $-123,411$ & $-135,409$ \\
\hline Pago de intereses y comisiones & -953 & -306 & 8 \\
\hline Pagos a trabajadores y otros & $-23,252$ & $-26,059$ & $-25,930$ \\
\hline Pago de tributos & $-4,957$ & $-8,498$ & $-6,701$ \\
\hline $\begin{array}{l}\text { Otros cobros de operación } \\
\text { Efectivo neto proveniente de las }\end{array}$ & 619 & 1,153 & _915, \\
\hline \multicolumn{4}{|l|}{ Actividades de inversión } \\
\hline Adquisición de propiedad, planta y equipo & $-7,231$ & $-17,726$ & $-12,936$ \\
\hline Venta de propiedad, planta y equipo & 120 & 1,002 & 491 \\
\hline Compra de Activos Intangibles/ & -326 & -588 & -213 \\
\hline Aporte de capital en subsidiarias (Compra c & $-15,628$ & -536 & -248 \\
\hline $\begin{array}{l}\text { Prestamos Concedidos a Entidades Relaciol } \\
\text { Efectivo neto utilizado en las actividades }\end{array}$ & - & $-2,100$ & $-10,900$ \\
\hline de inversión & $-23,065$ & $-19,948$ & $-23,806$ \\
\hline Aumento de obligaciones financieras & 81,000 & 63,004 & 152,993 \\
\hline Amortización o Pago de Obligaciones Finan & $-117,564$ & $-60,000$ & -165,617 \\
\hline de las actividades de financiamiento. & $-36,564$ & 3,004 & $-12,624$ \\
\hline Aumento (Disminución) Neto de Efectivo y & 18,444 & $-3,410$ & $-20,751$ \\
\hline Diferencia en cambio del efectivo y equiva & 221 & 87 & - \\
\hline Saldo de efectivo y equivalente de efectivc & 5, 980 & 24,645 & $21,322$. \\
\hline Saldo de efectivo y equivalente de & & & \\
\hline Eefectivo al cierre del año. & 24,645 & 21, 322 & I \\
\hline
\end{tabular}




\section{Anexo 4 Estado de Cambios en el Patrimonio}

EXSA S.A.

Estado de Cambio en el Patrimonio Neto (Expresado en Miles de USD (000)

\begin{tabular}{|c|c|c|c|}
\hline CONCEPTOSI FECHAS & 2015 & 2016 & 2017 \\
\hline Patrimonio Neto Inicial: & 100,549 & 108,017 & 111,467 \\
\hline Utilidad/(Pérdida) Neta & $-6,958$ & 3,432 & 3,766 \\
\hline \multicolumn{4}{|l|}{ Acciones Laborales } \\
\hline \multicolumn{4}{|l|}{ Ajuste Patrimonial } \\
\hline \multicolumn{4}{|l|}{ Aportes de Capital } \\
\hline \multicolumn{4}{|l|}{ Revaluación Voluntaria del Activo Fijo } \\
\hline \multicolumn{4}{|l|}{ Dividendos/Utilidades entregadas } \\
\hline \multicolumn{4}{|c|}{ Ganancias por instrumentos derivados financieros } \\
\hline \multicolumn{4}{|l|}{ Compra de acciones subsidiarias } \\
\hline Otras Deducciones (otro resultado integral) & 14,426 & 18 & 3 \\
\hline Ajustes & - & - & - \\
\hline Patrimonio Neto Final: & 108,017 & 111,467 & 115,236 \\
\hline Cambio Neto Patrimonial: & 7,468 & 3,450 & 3,769 \\
\hline VERIFICACION CUADRE DE RECONCILIACIOI & 7,468 & 3,450 & 3,769 \\
\hline
\end{tabular}

